\title{
A Decision-Making Model for Soil Stabilization: Minimizing Cost and Environmental Impacts
}

by

ABSTRACT: Studies have examined the environmental impacts of soil stabilization, however the costs of distinct dosages for such technique remain unexplored. Indeed, it is not yet clear whether there is a trade-off between cost and environmental impacts for soil stabilization dosages. This technical note seeks to address this gap by performing an economic analysis of three dosage strategies (high binder/low dry unit weight, medium binder/medium dry unit weight, low binder/high dry unit weight) considering five values for porosity-binder index and strength and stiffness as performance parameters. Such results were then combined with environmental impact data to create a decision-making model for optimal dosages considering the economic and environmental dimensions of sustainability. An example for road base $\left(q_{u}=\right.$ $1,034 \mathrm{kPa}$ ) is presented here to illustrate how the model can be applied in real-world projects. Such $q_{u}$ corresponds to a porosity-binder index of 32.44 which can be attained by different combinations of dry unit weight and binder content ranging, respectively, from 16 to $19 \mathrm{kN} / \mathrm{m}^{3}$ to 3 to $7 \%$. Using the proposed model, the dosage with minimal cost and environmental impacts could be determined: lime content of $3 \%$ and dry unit weight of $17.44 \mathrm{kN} / \mathrm{m}^{3}$. Binder was found to be the main contributor for cost and environmental impacts, indicating that dosages with minimal binder content and maximum dry unit weight should be preferred. The findings presented here suggest that there is not a trade-off between environmental and economic pillars and dosages with minimal cost and impacts can be created.

Keywords: soil stabilization; economic and environmental pillars; geotechnical engineering; sustainability.

${ }^{1}$ Lecturer, School of Civil and Environmental Engineering, University of Technology Sydney (UTS), Sydney NSW 2007, Australia. E-mail: cecilia.rocha@uts.edu.au

${ }_{2}$ Ph.D. candidate, Dept. of Civil, Environmental and Mining Engng., The University of Western Australia, Australia. E-mail: eduardo.bittarmarin@research.uwa.edu.au

3 Ph.D. candidate, Graduate Program in Civil Engng., Universidade Federal do Rio Grande do Sul, Brazil. E-mail: alejandro.quinonez@ufrgs.br

${ }^{4}$ Professor of Civil Engineering, Graduate Programme in Civil Engineering, Universidade Federal do Rio Grande do Sul, Brazil. E-mail: consoli@ufrgs.br (corresponding author) 


\section{Introduction}

Geotechnical engineering accounts for a large portion of resources used in a project (Holt et al. 2010; Abreu et al. 2008) as it involves a considerable amount of materials and energy. Thus, it provides an important element in the agenda towards more sustainable development (Holt et al. 2010). Geotechnical engineering entails the design and production of foundations, earthworks, retaining walls, and subgrades required for buildings and/or infrastructure projects (airports, ports, roads, etc.). Such a sector creates major changes in the landscape that are long lasting and resource intensive (Jefferis 2008). Yet, research on sustainability in this sector is still scarce (Holt et al. 2010; Jefferis 2008; Rocha et al. 2016). In addition, most studies focus solely on the environmental aspect. For instance, Jefferson et al. (2010) compared the carbon dioxide emissions of vibro-columns using varied materials, whereas Egan and Slocombe (2010) analyze such emissions for three-ground improvement methods (vibro-columns, deep dynamic compaction, and piling). A number of studies also looked at the impact for varied environmental categories for soil stabilization for road sub-base (e.g. Jones and Hammond 2008; The World Bank 2010; Celauro et al. 2015; Sabnis et al. 2015).

Basu et al. (2015) suggest a system engineering approach incorporating the three E's (environment, equity and economy) to overcome the emphasis on cost as an objective and social and environmental impacts as constraints. However, the referenced authors noticed conflicts, particularly between (i) economic growth and environmental protection and (ii) economy and equity (uneven distribution of wealth). Pope et al. (2004) also observed such a difficulty (i.e. to integrate the social, environmental, and economic interactions and trade-offs) in reviewing sustainability assessments. Indeed, sustainable engineering problems can be defined as wicked since they are unique, difficult to formulate, and have competing objectives so multiple but incompatible solutions can be developed (Basu et al. 2015). Singh et al. (2012) also reviewed a number of indices that have been implemented to measure sustainable development. The benefits include the normalization and aggregation according to statistical methods and scientific rules, yet only a few include environmental, economic, and social considerations with most indices focused on one dimension only (Singh et al. 2012). This also holds true for geotechnical engineering where most studies focus solely on the environmental assessment of solutions.

Soil stabilization, entailing physical (soil compaction) and/or chemical (addition of small amounts of a binder - such as lime, pozzolan-lime, Portland cement or geopolymers) techniques, can be used to enhance the mechanical performance of soils (e.g. Ingles and Metcalf 1972; Consoli et al. 2012, 2018a, 2018b, 2019a, 2019b, 2020a, 2020b; Arulrajah et al. 2018; Al-Taie et al. 2019; Yaghoubi et al. 2019; Donrak et al. 2020). This provides an alternative to traditional practice, namely, to replace the soil by natural material deposit (sand, crushed rock, etc.) with improved characteristics (e.g. Ingles and Metcalf 1972, Mitchell 1981, Terashi and Juran 2000). However, such practice creates a number of problems from economic and environmental perspectives such as the (i) extraction and usage of raw materials, (ii) 
transportation of such material from the deposit to the construction site, and (iii) transportation and disposal of the soil (e.g., Terashi and Juran 2000, Saldanha 2018). Yet, these problems can be minimized using soil stabilization. For instance, the design of a nuclear power plant in South Africa involved the construction of a unit over approximately 5.5-m thick layer of medium dense saturated sand (Dupas and Pecker 1979). Three solutions were proposed (Dupas and Pecker 1979): (1) deep foundations; (2) excavation and backfill with ripped shale from a rock deposit a few kilometers away; and (3) excavation and backfill with local sand-cement stabilization. The third option provided the most economic solution and was thus adopted.

Ground improvement techniques can be used to enhance the performance of most soils (e.g. clays, sands, silts, etc.) but are mandatory for some. This is the case of dispersive clays, which are highly erodible in the presence of water, leading to problems such as tunnel erosion (Hardie et al. 2017) and catastrophic earth piping in earthen dams (Sherard et al. 1976; Gutierrez et al. 2003). Hardie (2009) presents a complete study of dispersive soils and their management. The author details the causes and consequences of soil dispersion and erosion process approaches for minimizing erosion risks in dispersive soil using compaction and chemical techniques, as well as activities that increase the risk of erosion on dispersive soils. Dispersive soil occurs in several countries all over the world including Australia, South Africa, USA, Brazil, Argentina, Bolivia, India, amongst others (Ingles and Metcalf 1972; Bell and Maud 1994; Abbaslou et al. 2016). According to the Encyclopedia Britannica (2018), in 60\% of the total region of Paraguay, dispersive clay can be found. Yet, such soils can be completely converted into non-dispersive soils by the addition of chemical modifiers such as lime (USBR 1998).

This technical note expands the scope of sustainability analysis in geotechnical engineering by assessing fifteen dosages options to stabilize a dispersive clay from economic and environmental viewpoints. It should be highlighted that the procedure adopted here for calculating the direct cost of the fifteen dosages follows the same one adopted in a road construction project in the Paraguayan Chaco carried out by a consortium of companies, in which the second and third authors of this manuscript took part. The soil stabilization involved both (i) compaction (dry unit weight increase) and (ii) addition of binder (lime), which have been extensively reported to improve soils performance (e.g., Jayasinghe and Kamaladasa, 2007; Ciancio and Gibbings, 2012; Consoli et al., 2016a, 2016b). The dispersive clay examined here covers roughly all the western part of Paraguay territory (about 250,000 km² approximately $60 \%$ of the total area of the country), named Paraguayan Chaco (Encyclopedia Britannica 2018). This is the most undeveloped region of the country due to such problematic soil, which precludes an effective network of road (needed for the transportation of resources across the country) to be created (Quiñónez Samaniego 2015). In addition, deposits of natural materials (for replacing this dispersive clay) are only available in distant locations (usually above 300-km) (Encyclopedia Britannica 2018). As a result, soil stabilization becomes the only economic and environmental alternative to improve the soil 
performance.

Yet, the cost implications of these procedures (physical-chemical ground improvement techniques) remain unexplored. Thus, three dosage strategies (low-binder/high-dry unit weight, mediumbinder/medium dry unit weight, and high-binder/low-dry unit weight) were examined for three performance parameters (tensile and compressive strength and stiffness) providing answers to the following questions. What are the economic implications of increasing binder content? What are the economic implications of increasing dry unit weight? Can a dosage be optimized both in terms of cost and environmental viewpoints? This technical note also proposes a decision-making model for devising optimal dosages considering the economic and environmental pillars of sustainability. As demonstrated by the application detailed here there is not a trade-off between these two pillars, namely, dosages with minimal cost and environmental impacts can be attained.

\section{Strength and stiffness}

The soil studied herein is classified as a lean clay (CL) according to ASTM D 2487 (ASTM 2017). Its total dissolved salts (TDS) reach $15.2 \mathrm{mEq} / \mathrm{L}$, with a percentage of sodium (PS) of $91.4 \%$. According to Sherard et al. (1976), a relationship of pore water salts and dispersion of compacted soil samples measured in laboratory with a pinhole test suggested that soils with TDS superior to $1.0 \mathrm{mEq} / \mathrm{L}$ and PS higher than $60 \%$, which encloses presently studied clay, might be considered dispersive. The main physical properties of the studied dispersive clay are: $43 \%$ liquid limit, $24 \%$ plastic index, 2.74 specific gravity, $34 \%$ clay (diameter $<0.002-\mathrm{mm}), 59 \%$ silt $(0.002-\mathrm{mm}<$ diameter $<0.075-\mathrm{mm})$ and $7 \%$ fine sand $(0.075-$ $\mathrm{mm}<$ diameter $<0.425-\mathrm{mm}$ ), the mean particle diameter is $0.005-\mathrm{mm}$, and the maximum dry unit weight and the optimum moisture content for modified Proctor compaction effort are $19.0 \mathrm{kN} / \mathrm{m}^{3}$ and $13 \%$, respectively. Consoli et al. (2016a) have shown that independently of the dry unit weights considered, the studied clay has shown to change from moderately dispersive when no lime is added to nondispersive for amounts of lime insertion of $3 \%$ or above (the lime range studied herein varied from $3 \%$ to $7 \%$ ). The plastic index of the soil reduced from $24 \%$ (without lime addition) to about $15 \%$ (soil with $3 \%$ to $7 \%$ of lime) due to lime addition. A dolomitic hydrated lime with a specific gravity of 2.60 was used.

The strength and stiffness of the compacted soil-lime blends examined here can be predicted by equations involving the porosity-lime index $\left(\eta / L_{i v}\right)$, where $\eta$ is the porosity of the compacted soil-lime blends and $L_{i v}$ is the volumetric lime content. Such index has been found to be appropriate to estimate the performance of varied soils (clays, silts, etc.) for a number of parameters such as strength, stiffness, and durability (Consoli et al. 2016a, 2018a, 2018b). Equations 1-3, 4-6, and 7-9 provide a good fit (all $\mathrm{R}^{2}$ above 0.91 ) for compressive strength $\left(q_{u}\right)$ for 60,28 , and 7 days, tensile strength $\left(q_{t}\right)$ for 60,28 , and 7 days, and initial shear modulus $\left(G_{0}\right)$ for 60,28 , and 7 days, respectively, as detailed in Consoli et al. (2016a). Such equations establish a one-to-one relationship between the index $\left(\eta / L_{i v} 0.16\right.$ for the blends examined here) and a target performance value (strength or stiffness) for a given curing period $(60,28$, 
or 7 days). Equations 10 and 11 detail the calculation of porosity and volumetric lime content (both nondimensional), which are used to obtain the porosity-lime index.

$q_{u}(k P a)=1.80 * 10^{8}\left[\frac{\eta}{\left(L_{i v}\right)^{0.16}}\right]^{-3.4}$

$q_{u}(k P a)=1.42 * 10^{8}\left[\frac{\eta}{\left(L_{i v}\right)^{0.16}}\right]^{-3.4}$

$q_{u}(k P a)=1.02 * 10^{8}\left[\frac{\eta}{\left(L_{i v}\right)^{0.16}}\right]^{-3.4}$

$q_{t}(k P a)=2.56 * 10^{7}\left[\frac{\eta}{\left(L_{i v}\right)^{0.16}}\right]^{-3.4}$

$q_{t}(k P a)=1.87 * 10^{7}\left[\frac{\eta}{\left(L_{i v}\right)^{0.16}}\right]^{-3.4}$

$q_{t}(k P a)=1.31 * 10^{7}\left[\frac{\eta}{\left(L_{i v}\right)^{0.16}}\right]^{-3.4}$

$G_{0}(M P a)=1.56 * 10^{7}\left[\frac{\eta}{\left(L_{i v}\right)^{0.16}}\right]^{-2.6}$

$G_{0}(M P a)=1.25 * 10^{7}\left[\frac{\eta}{\left(L_{i v}\right)^{0.16}}\right]^{-2.6}$

$G_{0}(M P a)=1.04 * 10^{7}\left[\frac{\eta}{\left(L_{i v}\right)^{0.16}}\right]^{-2.6}$

$\eta=100\left[1-\frac{\gamma_{d}}{1+\frac{L}{100}}\left(\frac{1}{\gamma_{s_{S}}}+\frac{L}{100 \times \gamma_{s_{L}}}\right)\right]$

$L_{i v}=100\left(\frac{\gamma_{d}}{1+\frac{L}{100}}\right)\left(\frac{L}{100 \times \gamma_{s_{L}}}\right)$

where $\gamma_{d}$ is the dry unit weight of the blend, $L$ is the lime content (expressed in relation to mass of dry soil) and $\gamma_{s_{S}}$ and $\gamma_{s_{L}}$ are the unit weight of solids of the soil and unit weight of solids of the lime, respectively.

Five target values for $\eta / L_{\text {iv }} 0.16$ organized in five groups (B-F as shown in Table 1) were examined. It is worth highlighting that due to the one-to-one relationship detailed above, each value for $\eta / \mathrm{Liv}^{0.16}$ results in a single value in terms of strength $\left(q_{u}\right.$ or $\left.q_{t}\right)$ or stiffness $\left(G_{0}\right)$ for each curing period. For instance, entering $\eta / L_{\text {iv }} 0.16=33.07$ (group B) in Equation 1 results in a target performance value of $696.1 \mathrm{kPa}$ (for 7 days of curing). For each group, low, medium, and high levels for binder content and dry unit weight were investigated, leading to three dosage strategies: high dry unit weight/low binder (B3, C3, D3, E3, and F3), medium dry unit weight/medium binder ( $\mathrm{B} 5, \mathrm{C} 5, \mathrm{D} 5, \mathrm{E} 5$, and $\mathrm{F5}$ ), and high dry unit weight/low binder (B7, $\mathrm{C7}, \mathrm{D7}, \mathrm{E7}$, and F7). Low binder/low dry unit weight or high binder/high dry unit weight strategies cannot be formulated since a low binder content has to be counterbalanced by a high dry unit weight (or viceversa) to attain a given $\eta / \mathrm{L}_{\mathrm{i}}{ }^{0.16}$ (or target performance value). Indeed, all dosages in group B (B3, B5, and $\mathrm{B} 7$ ) provide the same $\eta / \mathrm{L}_{\mathrm{iv}}{ }^{0.16}$ value (33.07) and thus target performance value but with varying levels of binder content and dry unit weight (Table 1): low binder/high dry unit weight (B3 with $L=3 \%$ and $\left.\gamma_{d}=17.28 \mathrm{kN} / \mathrm{m}^{3}\right)$, medium binder/medium dry unit weight (B3 with $L=5 \%$ and $\left.\gamma_{d}=16.52 \mathrm{kN} / \mathrm{m}^{3}\right)$, and high binder/low dry unit weight (B7 with $L=7 \%$ and $\left.\gamma_{d}=16.00 \mathrm{kN} / \mathrm{m}^{3}\right)$. 
Tensile and compressive strength $\left(q_{u}\right.$ or $\left.q_{t}\right)$ and initial shear modulus $\left(G_{0}\right)$ are commonly used parameters to assess strength and stiffness in geotechnical projects (e.g., Mitchell 1981, Consoli et al. 2018a), and thus were adopted in this study. The minimum amount of lime (3\%) was defined according to the lime fixation point method (Hilt and Davidson 1960). Such a method determines the minimal amount of binder required for cementitious reactions to create cohesion among soil particles. On the other hand, the maximum amount of lime (7\%) was defined according to Mitchell (1981) that suggests up to $7 \%$ for the stabilization of clayey soils. The studied densities were defined according to the modified Proctor compaction test (ASTM D1557 2012) of soil-lime blends (using the $5 \%$ of lime as base). The modified Proctor compaction effort results for soil - $5 \%$ of lime (average value of lime in weight) blends indicated a maximum dry unit weight of $19 \mathrm{kN} / \mathrm{m}^{3}$ and the optimum moisture content of $13 \%$, the same values as for the soil compaction results without lime. So, the high-dry unit weight value was established as the maximum dry unit weight of $19 \mathrm{kN} / \mathrm{m}^{3}$ under modified Proctor compaction effort. The dry unit weight values of $17.5 \mathrm{kN} / \mathrm{m}^{3}$ and $16.0 \mathrm{kN} / \mathrm{m}^{3}$ were considered as medium and low densities. So, the studied dry unit weight values $\left(16,17.5\right.$ and $\left.19 \mathrm{kN} / \mathrm{m}^{3}\right)$ are seen to be attained by equipments that transfer low, medium, and high compaction energies to the soil. The moisture content of $13 \%$ was kept the same for all dry unit weights.

\section{Cost calculation}

Figure 1 outlines the direct cost calculation for the fifteen dosages examined here, considering five elements: Lime production (1), Lime Transportation (2), Soil Extraction (3), Soil Transportation (4), and Mixing and Compaction (5). Such costs comprise material, personnel, and equipment. The total cost of each element is a product of: (i) Quantity ( $\mathrm{kg} / \mathrm{kg}-\mathrm{m}^{3} / \mathrm{m}^{3}$ of material or number of machinery or worker) presented in Column I, (ii) Consumption (demand for material or the inverse of productivity for machinery) presented in Column II, and (iii) Unitary Cost (dollar per kilogram of material, dollar per cubic meter of blends, or dollar per hour of machinery usage). The Productivity for equipment (Column III in Figure 1) including the calculation for Variables $\mathrm{C}$ to $\mathrm{H}$ (Table 2) was carried out according to the Manual de Custos Rodoviários (2003). The unitary cost of equipment per hour (Table 3) (entered in Column IV Figure 1) and the sub-variables (Table 4) used to calculate their productivity (entered in Column III Figure 1) were based on the formulations in the Caterpillar Performance Handbook (2016).

The total costs for Lime Production (1) is the result of Variable A (Column II) multiplied by a 1.05 , which considers $100 \%$ of selected dosage of lime plus $5 \%$ of it to consider the possible loss of lime occurring during lime application (Column I) and by the lime unitary cost (Column IV). Variable A is dependent on the dosage selected. For instance, if the stabilized soil considers $5 \%$ of lime and a dry unit weight of $17.50 \mathrm{kN} / \mathrm{m}^{3}$ (D5 in Table 1), $83.33 \mathrm{~kg}$ of lime is required to produce $1 \mathrm{~m}^{3}$ of this lime-soil blend (Figure 2). 0.14 US\$/kg was the price of lime according to the company's database at that time. Moreover, 
the lime supplier transports the material to the workplace and the cost was 0.07 US\$ $/ \mathrm{kg}$ for the Lime transportation (2) process.

Soil extraction (3) and Soil transportation (4) are related since they both involve earthmoving operations, which include loosening, excavating, loading and hauling. This earthwork requires the use of an excavator, dump trucks and a worker to help the operator and truck drivers. The productivity of the excavator and dump trucks is shown in Table 2. Considering the use of one excavator $\left(100 \mathrm{~m}^{3} / \mathrm{h}\right)$ and a mean transport distance of $20 \mathrm{~km}$, four dump trucks (at a unitary cost of $31.25 \mathrm{~m}^{3} / \mathrm{h}$ each) are required to close the excavation and hauling circuit (with some machine-idle time in queue). Machines hourly costs are shown in Table 3. A cannon of $1.50 \mathrm{US} \$ / \mathrm{m}^{3}$ of soil was charged to the company by the landowner. Variable $B$ depends on the projected dosage and represents the quantity of excavated and transported loose soil necessary to perform $1 \mathrm{~m}^{3}$ of compacted stabilized soil $\left(1.08 \mathrm{~m}^{3} / \mathrm{m}^{3}\right.$ for dosage D5 in Table 2). Thus, once the cost of each sub-item (3.1, 3.2 and 3.3) is calculated, (through the product of Column I, Column II and Column IV) they are summed to obtain the cost to excavate $1 \mathrm{~m}^{3}$ of soil but in loose condition. In order to obtain the necessary cost for $1 \mathrm{~m}^{3}$ of compacted and stabilized lime-soil, this result is multiplied by Variable B (which depends on dosages) to calculate the Soil extraction item cost. The same procedure is carried out to estimate the Soil transportation cost.

Once the soil is placed in site, it is properly spread whit the motor grader and prepared for mixing with the disc harrow tractor. Lime and water are added depending on the projected lime-soil dosage following by mixing using the road cold recycler. Finally, the mixture is compacted with roller compactors to the projected dry unit weight $\left(17.50 \mathrm{kN} / \mathrm{m}^{3}\right.$ for dosage D5 in Table 1) and the motor grader performs a leveling termination. Two workers are necessary to operate the machine. The cost estimations described in the previous paragraph is summarized in Fig. 1 for a general application. As explained before, the cost of mixing and compacting of $1 \mathrm{~m}^{3}$ of lime-soil is the product of Column I (quantity of machines), Column II (hours-machine consumed) where variables $\mathrm{C}$ to $\mathrm{H}$ are machine productivities dependent on the project dosages shown in Table 2, and Column IV (hourly machine cost in Table 3). Fig. 2 shows the estimate cost for dosage D5 from Table 1. Therefore, the total cost of producing $1 \mathrm{~m}^{3}$ of lime stabilized base or sub-base is the summation of the items $(1,2,3,4,5.1$ and 5.2) in the column TOTAL COSTS PER UNIT in Fig. 1.

Figure 2 details the cost calculation for D5 in order to exemplify the procedure adopted for the other fourteen dosages. The second and third columns in Table 2 detail the calculation of Variables A for D5 $\left(\gamma_{d}=17.5 \mathrm{kN} / \mathrm{m}^{3}, w=13 \%\right.$ and $\left.L=5 \%\right)$ : Variable $A$ is equal to $83.33 \mathrm{~kg} / \mathrm{m}^{3}$, Variable $B$ is equal to 1.08 $\mathrm{m}^{3} / \mathrm{m}^{3}$, Variable $C$ is equal to $86.97 \mathrm{~m}^{3} / \mathrm{h}$, Variable $D$ is equal to $71.83 \mathrm{~m}^{3} / \mathrm{h}$, Variable $E$ is equal to 124.89 $\mathrm{m}^{3} / \mathrm{h}$, Variable $F$ is equal to $199.56 \mathrm{~m}^{3} / \mathrm{h}$, Variable $G$ is equal to $136.47 \mathrm{~m}^{3} / \mathrm{h}$, and Variable $H$ is equal to 384.62 m³h. Lime Production (1), Lime Transportation (2), Soil Extraction (3), Soil Transportation (4), and Blends Production (5), namely, Mixing (5.1) and Compaction (5.2), account respectively for: 12.25 US\$; 
6.13 US\$; 2.70 US\$; 4.36 US\$; 2.95 US\$; and 0.38 US $\$$ per cubic meter of blend (last column in Figure 2). The total cost for D5 per cubic meter of blend is the summation of these six values, which results in 28.77 US\$

\section{Results}

Figure 3 depicts the total cost and environmental impacts for the fifteen dosages examined. It also shows the contribution of the five processes: Lime production (1), Lime transportation (2), Soil extraction (3), Soil transportation (4), and Blends production (5). The cost information (contained in Figure 3a) arises from the calculations detailed in the previous sections. The environmental information (contained in Figs. 3b, 3c, and 3d) was computed based on the data presented in Da Rocha et al. (2016). More specifically, it was obtained by adopting the procedure (i.e. multiplication of two matrices presented in that paper) described in Da Rocha et al. (2016).

For each group, the low binder/high dry unit weight dosage provides the lowest cost and environmental impacts and the high binder/low dry unit weight dosage provides the highest cost and environmental impacts. For example, the three dosages in group D provide the same performance (Table 1). Yet, D3 ( $\gamma_{d}=18.20 \mathrm{kN} / \mathrm{m}^{3}$ and $\left.\mathrm{L}=3 \%\right)$ provides such performance at the lowest cost (US\$22.63) whereas D7 ( $\gamma_{d}=17.02 \mathrm{kN} / \mathrm{m}^{3}$ and $\mathrm{L}=7 \%$ ) provides it at the highest cost (US\$34.63) (Figure 3a). Likewise, D3 provides minimal environmental impacts $\left(506.0 \mathrm{MJ} ; 59.1 \mathrm{~kg}\right.$ of $\mathrm{CO}_{2}$-eq.; and $9.21 \mathrm{E}-03 \mathrm{~kg}$ of $\mathrm{C}_{2} \mathrm{H}_{4}$-eq.) whereas D7 provides the highest impacts $\left(976.3 \mathrm{MJ} ; 118.4 \mathrm{~kg}\right.$ of $\mathrm{CO}_{2}$-eq.; and $1.83 \mathrm{E}-02 \mathrm{~kg}$ of $\mathrm{C}_{2} \mathrm{H}_{4}$-eq.) as shown in Figures $3 \mathrm{~b}, 3 \mathrm{c}$, and $3 \mathrm{~d}$ ).

Lime production (1) is the main cost of component, accounting for $34 \%$ to $47 \%$ of the total cost considering all fifteen dosages examined. Indeed, at least $50 \%$ of the total cost for all dosages examined is required for Lime production (1) and Lime transportation (2), suggesting that low binder/high dry unit weight dosages should be preferred from an economic perspective. As for the environmental impact (carbon dioxide emission, photochemical oxidation, and embodied energy), Lime production (1) accounts for more than $80 \%$ of the impacts, measured in $\mathrm{MJ}$; $\mathrm{kg}_{\text {of }} \mathrm{CO}_{2}$-eq.; or $\mathrm{kg}$ of $\mathrm{C}_{2} \mathrm{H}_{4}$-eq. per cubic meter of blend. Blends production (5) has the second biggest contribution for such impacts, but accounts for less than $10 \%$ of the total impact. Such results further support the need for dosages that minimize binder content (and thus maximize dry unit weight) as this is the main contributor for cost and environmental impacts.

\section{Decision-making model for optimal dosages from economic and environmental viewpoints} In this section, a graphical use of the decision-making model for optimal dosages is described. Figs. 4(ag) show the decision-making model considering the economic and environmental pillars of sustainable development. In a first stage, the target value for the desired performance is determined, so the porosity- 
binder index $\left(\eta / L_{i v}{ }^{0.16}\right)$ required for such performance is obtained. Several mixtures design and protocols can be found in the literature and the strength requirements for using lime stabilized solutions as structural layers in pavement systems vary considerably from agency to agency (Little 1998). In this example, the mixture design is defined by Thompson (1970) criteria showed in Table 5 for bases in no freeze-thaw activity on structural layer. Thus, 28 days of curing minimum strength of $1,034 \mathrm{kPa}$ in unconfined compressive strength is selected for the design of base layers. The porosity-binder index $\left(\eta / L_{i v}{ }^{0.16}\right)$ required for such performance is then 32.44 according to point A in Fig. 4(c). Moreover, in cases where more than one design parameter is required, other performance requirements such as initial shear modulus [Figure 4(a)], and tensile strength [Figure 4(b)] can be assessed for the design porosity-binder index.

The porosity-binder index 32.44 (required for the compressive strength for the example considered) can be attained by different combinations of dry unit weight and binder contents as long as the base layer construction and compaction are possible. These combinations are represented by the quadrilaterals illustrated in Figs. 4(d-g) for economic and environmental impact evaluated in Fig. 3. Lines $L$ represent the variation of dry unit weights at constant lime contents ( $3 \%$ for $L_{3}$ and $7 \%$ for $\left.L_{7}\right)$ for different porosity-binder indexes whereas Lines $\gamma$ show the variation of lime contents at constant dry unit weights $\left(16 \mathrm{kN} / \mathrm{m}^{3}\right.$ for $\gamma_{16}$ and $19 \mathrm{kN} / \mathrm{m}^{3}$ for $\left.\gamma_{19}\right)$. Achievable dry unit weights are conditioned by the equipment to be used in field (compaction-rollers) whereas the minimum lime content ( $3 \%$ in this study) by methods such as the one described by Hilt and Davidson (1960). In this model, the maximum dry unit weight that can be achievable by typical compaction-rollers is limited by the value obtained in modified Proctor tests $\left(19 \mathrm{kN} / \mathrm{m}^{3}\right)$ and is represented by Lines $\gamma_{19}[$ [Figs. $4(\mathrm{~d}-\mathrm{g})]$. The minimum lime content $(3 \%)$ is represented by Lines $L_{3}[$ Figures $4(\mathrm{~d}-\mathrm{g})]$. Therefore, optimum dosages (low binder/high dry unit weight) are captured by solid lines Line $L_{3}$ and Line $\gamma_{19}$ in Figs. $4(\mathrm{~d}-\mathrm{g})$, and their intersections (points I) depict the minimum porosity-binder index $\left(\eta / L_{i v} 0.16=26.94\right)$ available for optimum lowest binder $(L=3 \%) /$ highest $d r y$ unit weight $\left(\gamma_{\mathrm{d}}=19 \mathrm{kN} / \mathrm{m}^{3}\right)$. For optimum porosity-binder index less than 26.94 an increment on lime content is inevitable (points will be on Lines $\gamma_{19}$ ).

Finally, the minimal values of cost and environmental impacts (embodied energy, carbon dioxide emission, or photochemical oxidation) obtained from these lines for the design $\eta / L_{i v} 0.16=32.44$ are evident by dashed arrows in Figures $4(\mathrm{~d}-\mathrm{g})$. Thus, the optimum low binder/high dry unit weight combination from $\eta / L_{i v} 0.16=32.44$ (for the compressive strength for the example considered) is composed by a lime content of $3 \%$ and dry unit weight of $17.44 \mathrm{kN} / \mathrm{m}^{3}$ deducted from soil phase relationships (Equations 10 and 11).

In terms of generalization of the proposed model and its applicability to other blends, it is worth highlighting that the $\left(\eta / L_{i v}\right)^{b}$ index with exponent "a" varying from 0.12 to 0.16 and exponent "b" varying 
from -4.1 to -3.4 has been found to be a good predictor of strength, among other properties for several blends for soil stabilization. These include clayey sand-lime blends (Consoli et al. 2014), clay-lime (Consoli et al. 2016b), sulfated clay-lime (Consoli et al. 2017) and silt-lime (Consoli et al. 2017). Also, the ranges for density and binder content are similar to the ones studied here: density varying from $11 \mathrm{kN} / \mathrm{m}^{3}$ to $19 \mathrm{kN} / \mathrm{m}^{3}$ and lime content varying from $3 \%$ to $9 \%$. As a result, the quadrilateral shape outlining all combinations of dry unit weight and binder contents presented in Figs. 4 and which provides the basis for the proposed decision-making model also applies to these other blends. Clearly, the dimension and steepness of the four lines forming the quadrilateral may vary depending on the particular properties of the blends, the range of values for density and binder content examined, the costs and environmental impacts of the studied materials, etc. However, the overall shape and also associated decision-making process apply. The latter can be summarized as follows: (1) Determine the $\eta / L_{i v}{ }^{a}$ value for the required performance ( $q_{u}, q_{t}, G_{0}$, etc.). (2) Check if such $\eta / L_{i}$ avalue falls in the quadrilateral line for minimal binder content ( $L_{3}$ in the example discussed here). (3) If that is the case, determine the required density (for the minimum lime content) to attain the $\eta / L_{i v}{ }^{a}$ value. (4) If that is not the case, namely, the value falls in the quadrilateral line for maximum density ( $\gamma_{19}$ in the example discussed here), determine the required binder content (for the maximum density) to attain the $\eta / L_{i}{ }^{a}$ value.

\section{Conclusions}

This technical note performed the economic analysis of three dosage strategies for soil stabilization (namely, high binder/low dry unit weight, medium binder/medium dry unit weight, and low binder/high dry unit weight) for three parameters (compressive and tensile strength, and initial shear modulus). Binder production and transportation (lime, for the soil examined here) is the main cost component for all dosages. It accounts for $52 \%$ (for low binder/high dry unit weight dosages) up to $71 \%$ (for high binder/low dry unit weight dosages) of the total cost. This indicates that minimizing binder content and maximizing dry unit weight (to attain a given porosity-binder index) creates the most cost-efficient dosage.

The cost results were combined with environmental impact data, namely, photochemical oxidation, global warming, and embodied energy, which were found to be the main categories affected by dry unit weight and binder content in Rocha et al. (2016). A decision-making model for devising optimal dosages considering the economic and environmental dimensions of sustainability was then proposed. The model was applied for a hypothetical case of road base $\left(q_{u}=1,034 \mathrm{kPa}\right.$ for 28 days of curing) to illustrate how the model can be applied in real world projects (Fig. 4). Interestingly, the model shows that low binder/high dry unit weight dosages perform better not only for cost but also for all environmental impact categories considered (photochemical oxidation, global warming, and embodied energy). Thus, the fundamental notion explored in the model is to minimize binder content and maximize dry unit weight. As a result, determining the threshold up to which dry unit weight can be increased (Lines $L_{3}$ ) and, 
subsequently, the porosity-binder values that can only be attained by increasing binder content even with maximum dry unit weight (Lines $\gamma_{19}$ ), become key.

This study contributes in expanding the scope of the still scarce literature in sustainability in geotechnical engineering by jointly performing an environmental and economic analysis of dosages considering three parameters $\left(q_{u}, q_{t}\right.$, or $\left.G_{0}\right)$. Unconfined compressive strength $\left(q_{u}\right)$ is often used as a main parameter for projects design (e.g. Ingles and Metcalf 1972; Mitchell 1981; Transportation Research Board 1987; Rogers et al. 1997; Consoli et al. 2009, 2019a). However, durability has been found to be a more appropriate parameter for dispersive soil such as the one examined here (Consoli et al. 2016a). Thus, further studies should apply the proposed model for other soils/binders (with the corresponding mechanical, economic, and environmental data for such materials) to expand the results presented herein: namely, that increasing dry unit weight is more environmental and cost effective than increasing binder content. Yet, additional performance parameters such as durability, resilient modulus or volumetric stability (also containing the porosity-binder index) might be more adequate to design high quality, sustainable and low-cost soil-lime geomaterials.

\section{Acknowledgements}

The authors acknowledge the financial support from the CNPq (Editais Universal, INCT and Produtividade em Pesquisa), FAPERGS/CNPq (PRONEX) and CAPES (PROEX). The authors also thank Mr. Hugo Carlos Scheuermann Filho for his assistance on the development of this manuscript.

\section{Data Availability}

Some or all data, models, or code that support the findings of this study are available from the corresponding author upon reasonable request. (unconfined compressive strength, splitting tensile strength and maximum shear modulus.) 


\section{References}

Abbaslou, H.; Hadifard, H.; and Poorgohardi, A. (2016). "Characterization of dispersive problematic soils and engineering improvements: a review." Computations and Materials in Civil Engineering, 1(2), 65-83.

Abreu, D. G.; Jefferson, I.; Braithwaite, P. A.; and Chapman, D. N. (2008). "Why is sustainability important in Geotechnical Engineering?" Geocongress 2008 - Geosustainability, Geohazards \& Mitigation, 821-828.

Al-Taie, A.; Disfani, M. M.; Evans, R.; and Arulrajah, A. (2019). "Collapse and swell of lime stabilized expansive clays in void ratio-moisture ratio-net stress space. International Journal of Geomechanics, 19(9), 04019105.

Arulrajah, A.; Yaghoubi, M.; Disfani, M. M. M.; Horpibulsuk, S.; Bo, M. W.; and Leong, M. (2018). "Evaluation of fly ash- and slag-based geopolymers for the improvement of a soft marine clay by deep soil mixing." Soils and Foundations, 58(6), 1358-1370.

ASTM (American Society of Testing and Materials) (2012). "Standard Test Methods for Laboratory Compaction Characteristics of Soil Using Modified Effort $\left(56,000 \mathrm{ft}-\mathrm{lbf} / \mathrm{ft} 3\left(2,700 \mathrm{kN}-\mathrm{m} / \mathrm{m}^{3}\right)\right)$." ASTM D 1557, West Conshohocken, Philadelphia.

ASTM (American Society of Testing and Materials) (2017). "Standard practice for classification of soils for engineering purposes (Unified Soil Classification System)." ASTM D 2487, West Conshohocken, Philadelphia.

Basu, D., Misra, A., Puppala, A. J. (2015). "Sustainability and geotechnical engineering: perspectives and review." Canadian Geotechnical Journal, 52, 96-113.

Bell, F. G.; and Maud, R. R. (1994). "Dispersive soils: a review from South African perspective." Quarterly Journal of Engineering Geology and Hydrogeology, 27(3), 195-210.

Donrak, J.; Horpibulsuk, S.; Arulrajah, A.; Kou, H.; Chinkulkijniwat, A.; and Hoy, M. (2020). "Wetting-drying cycles durability of cement stabilised marginal lateritic soil/melamine debris blends for pavement applications." Road Materials and Pavement Design, 21(2), 500-518.

Encyclopedia Britannica (2018). https://www.britannica.com/place/Paraguay/Land (visited on 18 December 2018).

Caterpillar Performance Handbook. (2016). 46 $6^{\text {th }}$ Ed., Caterpillar, Peoria, IL.

Celauro, C.; Corriere, F.; Guerrieri, M.; and Lo Casto, B. (2015). "Environmentally appraising different pavement and construction scenarios: a comparative analysis for a typical local road." Transp. Res. Part D. Transp. Environ. 34, 41-51.

Christian, J. (1981). "Management, machines, and methods in civil engineering." John Wiley \& Sons.

Christian, J.; and Xie, T. X. (1996). "Improving earthmoving estimating by more realistic knowledge." Canadian Journal of Civil Engineering, 23(1), 250-259.

Ciancio, D.; and Gibbings, J. (2012). "Experimental investigation on the compressive strength of cored and molded cement-stabilized rammed earth samples." Construction and Building Materials, 28, 294304.

Consoli, N. C.; Lopes Junior, L. S.; Foppa, D.; and Heineck, K. S. (2009). "Key parameters dictating strength of lime/cement treated soils." Proceedings of the ICE - Geotechnical Engineering, 162(2), $111-118$.

Consoli, N. C.; Johann, A. D. R.; Gauer, E. A.; Santos, V. R.; Moretto, R. L.; and Corte, M. B. (2012). "Key parameters for tensile and compressive strength of silt-lime mixtures." Géotechnique Letters, 2, 8185. 
Consoli, N.C., Lopes, L.S., Jr., Consoli, B.S., and Festugato, L. (2014). "Mohr-Coulomb failure envelopes of lime-treated soils." Géotechnique, 64(2), 165-170.

Consoli, N. C.; Quiñónez Samaniego, R. A.; and Kanazawa Villalba, N. M. (2016a). "Durability, strength and stiffness of dispersive clay-lime blends." Journal of Materials in Civil Engineering, 28(11), 04016124

Consoli, N. C.; Quiñónez Samaniego, R. A.; Marques, S. F. V.; Venson, G. I.; Pasche, E.; and González Velásquez, L. E. (2016b). "Single model establishing strength of dispersive clay treated with distinct binders." Canadian Geotechnical Journal, 53(12), 2072-2079.

Consoli, N. C.; Ibraim, E.; Diambra, A.; Festugato, L.; and Marques, S. F. V. (2017). "A sole empirical correlation expressing strength of fine-grained soils-lime mixtures." Soils and Rocks, 40(2), 147-153.

Consoli, N. C.; Winter, D.; Leon, H. B.; and Scheuermann Filho, H. C. (2018a). "Durability, strength, and stiffness of green stabilized sand." Journal of Geotechnical and Geoenvironmental Engineering, 144(9), 04018057.

Consoli, N. C.; Scheuermann Filho, H. C.; Godoy, V. B.; Rosenbach, C. M. D. C.; and Carraro, J. A. H. (2018b). "Durability of RAP-Industrial waste mixtures under severe climate conditions." Soils and Rocks, 41(2), 149-156.

Consoli, N. C.; Bittar Marin, E. J.; Quiñónez Samaniego, R. A.; Heineck, K. S., and Johann, A. D. R. (2019a). "Use of sustainable binders in soil stabilization." Journal of Materials in Civil Engineering, 31(2), 06018023.

Consoli, N. C.; Godoy, V.; Rosenbach, C. M. C.; and Peccin da Silva, A. (2019b). "Effect of sodium chloride and fibre-reinforcement on the durability of sand - coal fly ash - lime mixes subjected to freeze - thaw cycles." Geotechnical and Geological Engineering, 37(1), 107-120.

Consoli, N. C.; Festugato, L.; Scheuermann Filho, H. C.; Miguel, G. D.; Tebechrani Neto, A.; and Andreghetto, D. (2020a). "Durability assessment of soil-pozzolan-lime blends through ultrasonicpulse velocity test." Journal of Materials in Civil Engineering, 32(8), 04020223.

Consoli, N. C.; Bittar Marin, E. J.; Quiñónez Samaniego, R. A.; Scheuermann Filho, H. C.; and Cristelo, N. M. C. (2020b). "Field and laboratory behaviour of fine-grained soil stabilized with lime." Canadian Geotechnical Journal, DOI: 10.1139/cgj-2019-0271.

Departamento Nacional de Infraestrutura em Transportes (2003). "Manual de Custos Rodoviários." Vol. 4, Río de Janeiro, Brazil. (In Portuguese).

Dupas, J.-M.; and Pecker, A. (1919). "Static and dynamic properties of sand-cement." Journal of the Geotechnical Engineering Division, 105(GT3), 419-436.

Egan, D.; and Slocombe, B. C. (2010). "Demonstrating environmental benefits of ground improvement." Proceedings of the ICE - Ground Improvement, 163(1), 63-69.

Gransberg, D. D.; Popescu, C. M.; and Ryan, R. (2006). "Construction equipment management for engineers, estimators, and owners." CRC Press.

Gutierrez, F.; Desir, G.; and Gutierrez, M. (2003). "Causes of the catastrophic failure of an earth dam built on gypsiferous alluvium and dispersive clays (Altorricón, Huesca Province, NE Spain)." Environ. Geol., 43(7), 842-851.

Hardie, M. (2009). "Dispersive soils and their management: A technical reference manual." Department of Primary Industries and Water, Hobart, Australia.

Holt, D. G. A.; Jefferson, I.; Braithwaite, P. A.; and Chapman, D. N. (2010). "Sustainable geotechnical design." GeoFlorida 2010 Advances in Analysis, Modeling \& Design, 2925-2932.

Ingles, O. G.; and Metcalf, J. B. (1972). "Soil stabilization - Principles and practice." Butterworths, Melbourne, Australia. 
Jayasinghe, C.; and Kamaladasa, N. (2007). "Compressive strength characteristics of cement stabilized rammed earth walls." Construction and Building Materials, 21, 1971-1976.

Jefferis, S. A. (2008). "Moving towards sustainability in geotechnical engineering." GeoCongress 2008 Geosustainability, Geohazards \& Mitigation, 844-851.

Jefferson, I.; Gaterell, M.; Thomas, A. M.; and Serridge, C. J. (2010). "Emissions assessment related to vibro stone columns." Proceedings of the ICE - Ground Improvement, 163(1), 71-77.

Jones, C. I.; and Hammond, G. (2008). "Embodied energy and carbon in construction materials." Energy, 161(2), 87-98.

Little, D. N. (1998). "Evaluation of structural properties of lime stabilized soils and aggregates." National Lime Association.

Manual de Custos Rodoviários (2003). "Manual of road costs - methodology and concepts." Brazilian Ministry of Transportation, Brazil, 116 p. (in Portuguese).

Mitchell, J. K. (1981). "Soil improvement - state-of-the-art report." Proceedings of the $10^{\text {th }}$ International Conference on Soil Mechanics and Foundation Engineering. Int. Soc. of Soil Mechanics and Foundation Engng., 4, 509-565.

Pope, J.; Annandale, D.; and Morrison-Saunders, A. (2004). "Conceptualising sustainability assessment." Environmental Impact Assessment Review 24 (2004) 595-616.

Rocha, C. G.; Passuello, A.; Consoli, N. C.; Quiñónez Samaniego, R. A.; and Kanazawa Villalba, N. M. (2016). "Life cycle assessment for soil stabilization dosages: A study for the Paraguayan Chaco." Journal of Cleaner Production, 139, 309-318.

Rogers, C. D. F.; Glendinning, S.; and Roff, T. E. J. (1997). "Lime modification of clay soils for construction expediency." Proceedings of the ICE - Geotechnical Engineering, 125(3), 242-249.

Sabnis, A. S.; Mysone, P.; and Anant, S. (2015). "Construction materials - embodied energy footprint global warming: Interaction." Structural Engineers World Congress, Singapore.

Saldanha, R. B. (2018). "Fly ash, carbide lime and sodium chloride mixtures: unconfined compressive strength, durability and column leaching." Ph.D. thesis, Universidade Federal do Rio Grande do Sul, Porto Alegre, Brazil.

Sherard, J. L.; Dunnigan, L. P.; and Decker, R. S. (1976). "Identification and nature of dispersive soils." Journal of Geotechnical Engineering Division, 102(4), 69-87.

Singh, R. K.; Murty, H.R.; Gupta, S.K.; and Dikshit, A.K. (2012). "An overview of sustainability assessment methodologies." Ecological Indicators, 15 (2012) 281-299.

Terashi, M.; and Juran, I. (2000). "Ground improvement - State of the art." ISRM International Symposium 2000, Melbourne, Australia.

The World Bank (2010). "Greenhouse gas emissions mitigation in road construction and rehabilitation: A toolkit for developing countries." http://siteresources.worldbank.org/INTEAPASTAE/Resources/GHG-ExecSummary.pdf (visited on 13 January 2019).

Thompson, M. R. (1970). "Suggested method for mixture design procedure for lime-treated soils." In Special Procedures for Testing Soil and Rock for Engineering Purposes: Fifth Edition. ASTM International.

Transportation Research Board. (1987). "Lime stabilization-Reactions, properties, design, and construction." State of the Art Rep. No. 5, Transportation Research Board, Washington, D.C

USBR (United States Bureau of Reclamation) (1998). "Earth manual." U.S. Department of Interior, Washington, D.C. 
Yaghoubi, M.; Arulrajah, A.; Disfani, M. M.; Horpibulsuk, S.; Darmawan, S.; and Wang, J. (2019). "Impact of field conditions on the strength development of a geopolymer stabilized marine clay." Applied Clay Science, 167, 33-42. 
Table 1 - Dosages per different $\eta / L_{i v}{ }^{0.16}$ group (B, C, D, E and F).

538

\begin{tabular}{|c|c|c|c|c|c|c|c|c|c|c|c|c|c|c|c|}
\hline $\begin{array}{l}\text { SOIL } \\
\text { GROUP }\end{array}$ & \multicolumn{3}{|c|}{ B } & \multicolumn{3}{|c|}{$c$} & \multicolumn{3}{|c|}{ D } & \multicolumn{3}{|c|}{ E } & \multicolumn{3}{|c|}{$\mathrm{F}$} \\
\hline$\eta / \mathrm{Liv}^{0.16}$ & \multicolumn{3}{|c|}{33.07} & \multicolumn{3}{|c|}{32.27} & \multicolumn{3}{|c|}{29.78} & \multicolumn{3}{|c|}{28.26} & \multicolumn{3}{|c|}{26.98} \\
\hline $\begin{array}{l}q_{u}(\mathrm{kPa}) \\
7 \text { days }\end{array}$ & \multicolumn{3}{|c|}{696.1} & \multicolumn{3}{|c|}{756.2} & \multicolumn{3}{|c|}{993.9} & \multicolumn{3}{|c|}{1187.9} & \multicolumn{3}{|c|}{1385.5} \\
\hline $\begin{array}{l}q_{u}(\mathrm{kPa}) \\
28 \text { days }\end{array}$ & \multicolumn{3}{|c|}{969.1} & \multicolumn{3}{|c|}{1052.8} & \multicolumn{3}{|c|}{1383.6} & \multicolumn{3}{|c|}{1653.8} & \multicolumn{3}{|c|}{1935.8} \\
\hline $\begin{array}{l}q_{u}(\mathrm{kPa}) \\
60 \text { days }\end{array}$ & \multicolumn{3}{|c|}{1228.5} & \multicolumn{3}{|c|}{1334.5} & \multicolumn{3}{|c|}{1753.9} & \multicolumn{3}{|c|}{2096.4} & \multicolumn{3}{|c|}{2452.2} \\
\hline Dosages & B3 & B5 & B7 & $\mathrm{C} 3$ & $\mathrm{C} 5$ & $\mathrm{C7}$ & D3 & D5 & D7 & E3 & E5 & E7 & F3 & F5 & F7 \\
\hline$\gamma_{d}\left(\mathrm{kN} / \mathrm{m}^{3}\right)$ & 17.28 & 16.52 & 16.00 & 17.50 & 16.75 & 16.24 & 18.20 & 17.50 & 17.02 & 18.63 & 17.96 & 17.50 & 19.00 & 18.35 & 17.91 \\
\hline$\eta(\%)$ & 36.75 & 39.47 & 41.32 & 35.94 & 38.61 & 40.42 & 33.37 & 35.88 & 37.58 & 31.79 & 34.19 & 35.82 & 30.45 & 32.76 & 34.33 \\
\hline L (\%) & 3.0 & 5.0 & 7.0 & 3.0 & 5.0 & 7.0 & 3.0 & 5.0 & 7.0 & 3.0 & 5.0 & 7.0 & 3.0 & 5.0 & 7.0 \\
\hline $\operatorname{Liv}(\%)$ & 1.94 & 3.03 & 4.03 & 1.96 & 3.07 & 4.09 & 2.04 & 3.21 & 4.28 & 2.09 & 3.29 & 4.40 & 2.13 & 3.36 & 4.51 \\
\hline
\end{tabular}




\begin{tabular}{|c|c|c|}
\hline $\begin{array}{l}\text { VARIABLE I } \\
\text { MACHINE }\end{array}$ & EQUATION & EQUATION CONSIDERING DATA FOR DOSAGE D5 \\
\hline $\begin{array}{l}\text { Variable A } \\
{\left[\mathrm{kg} / \mathrm{m}^{3}\right]}\end{array}$ & $\frac{V_{\text {project }} \times L}{(1+L)}$ & $\frac{1,750 \times 0.05}{(1+0.05)}=83.33\left[\mathrm{~kg} / \mathrm{m}^{3}\right]$ \\
\hline $\begin{array}{l}\text { Variable B } \\
{\left[\mathrm{m}^{3} / \mathrm{m}^{3}\right]}\end{array}$ & $\frac{\gamma_{\text {project }}}{(1+L) \times \gamma_{\text {natural }}}$ & $\frac{1750}{(1+0.05) \times 1,550}=1.08\left[\mathrm{~m}^{3} / \mathrm{m}^{3}\right]$ \\
\hline $\begin{array}{l}\text { Excavator } \\
{\left[\mathrm{m}^{3} / \mathrm{h}\right]}\end{array}$ & $\frac{Q \times L f \times E_{f} \times 60}{T_{i}}$ & $\frac{1.5 \times 0.85 \times 0.85 \times 60}{0.65}=100\left[\mathrm{~m}^{3} / \mathrm{h}\right]$ \\
\hline $\begin{array}{l}\text { Dump Truck } \\
{\left[\mathrm{m}^{3} / \mathrm{h}\right]}\end{array}$ & $\frac{Q \times L f \times E_{f} \times 60}{T_{i}}$ & $\frac{12 \times 0.75 \times 0.85 \times 60}{14.69}=31.25\left[\mathrm{~m}^{3} / \mathrm{h}\right]$ \\
\hline $\begin{array}{l}\text { Motor Grader } \\
{\left[\mathrm{m}^{3} / \mathrm{h}\right]}\end{array}$ & $\frac{A_{w} \times e \times V_{e}}{n} \times E_{f} \times 1,000$ & $\frac{3.2 \times 0.2 \times 4 \times 0.75 \times 1,000}{30}=64\left[\mathrm{~m}^{3} / \mathrm{h}\right]$ \\
\hline $\begin{array}{l}\text { Variable C } \\
{\left[\mathrm{m}^{3} / \mathrm{h}\right]}\end{array}$ & $\frac{\frac{Q \times E_{f} \times 60}{T_{i}}}{\text { Variable A }}$ & $\frac{\frac{15,000[\mathrm{~kg}] \times 0.75 \times 60[\mathrm{~min} / \mathrm{h}]}{93.14[\mathrm{~min}]}}{83.33\left[\mathrm{~kg} / \mathrm{m}^{3}\right]}=86.97\left[\mathrm{~m}^{3} / \mathrm{h}\right]$ \\
\hline $\begin{array}{l}\text { Recycler } \\
{\left[\mathrm{m}^{3} / \mathrm{h}\right]}\end{array}$ & $\begin{array}{c}\text { Supplier recommendation for } 0.20 \mathrm{~m} \text {. } \\
\text { depth }\end{array}$ & $200\left[\mathrm{~m}^{3} / \mathrm{h}\right]$ \\
\hline $\begin{array}{l}\text { Variable D } \\
{\left[\mathrm{m}^{3} / \mathrm{h}\right]}\end{array}$ & $\frac{\frac{Q \times E_{f} \times 60}{T_{i}}}{\gamma_{\text {Project }} \times w}$ & $\frac{18,000[\mathrm{~L}] \times 0.75 \times 60[\mathrm{~min} / \mathrm{h}] / 49.56[\mathrm{~min}]}{1,750 \times 0.13\left[\mathrm{~L} / \mathrm{m}^{3}\right]}=71.83\left[\mathrm{~m}^{3} / \mathrm{h}\right]$ \\
\hline $\begin{array}{l}\text { Variable E } \\
{\left[\mathrm{m}^{3} / \mathrm{h}\right]}\end{array}$ & $\frac{A_{w} \times e \times V_{e}}{n} \times E_{f} \times \frac{V_{\text {natural }}}{V_{\text {project }}} \times 1,000$ & $\frac{2.35[\mathrm{~m}] \times 0.2[\mathrm{~m}] \times 4.0[\mathrm{~km} / \mathrm{h}]}{10} \times 0.75 \times \frac{1,550}{1,750} \times 1,000[\mathrm{~m} / \mathrm{km}]=124.89\left[\mathrm{~m}^{3} / \mathrm{h}\right]$ \\
\hline $\begin{array}{l}\text { Variable F } \\
{\left[\mathrm{m}^{3} / \mathrm{h}\right]}\end{array}$ & $\frac{\frac{Q \times E_{f} \times 60}{T_{i}}}{\gamma_{\text {project }} \times w}$ & $\frac{\frac{50,000[\mathrm{~L}] \times 0.75 \times 60[\mathrm{~min} / \mathrm{h}]}{49.56[\mathrm{~min}]}}{1,750 \times 0.13\left[\mathrm{~L} / \mathrm{m}^{3}\right]}=199.56\left[\mathrm{~m}^{3} / \mathrm{h}\right]$ \\
\hline $\begin{array}{l}\text { Variable G } \\
{\left[\mathrm{m}^{3} / \mathrm{h}\right]}\end{array}$ & $\frac{A_{w} \times e \times V_{e}}{n} \times E_{f} \times \frac{V_{\text {loose }}}{Y_{\text {project }}} \times 1,000$ & $\frac{1.74[\mathrm{~m}] \times 0.2[\mathrm{~m}] \times 4.5[\mathrm{~km} / \mathrm{h}]}{6} \times 0.75 \times \frac{1,220}{1,750} \times 1,000[\mathrm{~m} / \mathrm{km}]=136.47\left[\mathrm{~m}^{3} / \mathrm{h}\right]$ \\
\hline $\begin{array}{l}\text { Variable H } \\
{\left[\mathrm{m}^{3} / \mathrm{h}\right]}\end{array}$ & $\frac{A_{w} \times e \times V_{e}}{n} \times E_{f} \times \frac{V_{\text {natural }}}{V_{\text {project }}} \times 1,000$ & $\frac{1.93[\mathrm{~m}] \times 0.2[\mathrm{~m}] \times 3.0[\mathrm{~km} / \mathrm{h}]}{2} \times 0.75 \times \frac{1,550}{1,750} \times 1,000[\mathrm{~m} / \mathrm{km}]=384.62\left[\mathrm{~m}^{3} / \mathrm{h}\right]$ \\
\hline
\end{tabular}

Table 2 - Equations for obtaining Variable A-H and machine productivities (based on the Manual de Custos Rodoviários, 2003 and the Caterpillar Performance Handbook, 2016). 
Table 3 - Unitary cost (US\$/h) for company's equipment [based on formulations of the Caterpillar Performance Handbook (2016)].

\begin{tabular}{|l|l|c|c|}
\hline \multicolumn{1}{|c|}{ EQUIPMENT } & \multicolumn{1}{c|}{ MODEL } & HP & $\begin{array}{c}\text { PRICE } \\
\text { US\$/HOUR }\end{array}$ \\
\hline Excavator & \multicolumn{1}{|c|}{ CAT 336 DL } & 268 & 96.46 \\
\hline Dump truck & VOLKSWAGEN 16220 & 220 & 31.50 \\
\hline Motor grader & CAT 140H & 185 & 63.97 \\
\hline Lime spreader & STOLTZ & 115 & 35.20 \\
\hline Road cold recycler & CAT RM 350 & 430 & 118.04 \\
\hline Water spreader truck & VOLKSWAGEN 16220 - 18,000 Lts & 220 & 36.14 \\
\hline Tractor with steel blade disks & JOHN DEERE 7505 - 4x4 & 150 & 34.85 \\
\hline Water pump & JOHN DEERE - Diesel & 70 & 14.16 \\
\hline Pad foot roller & CAT 815 & 100 & 39.81 \\
\hline Tandem Vibratory Roller & DYNAPAC CC-421 & 118 & 34.36 \\
\hline
\end{tabular}

581 


\begin{tabular}{|c|c|c|c|c|c|c|c|c|c|c|c|}
\hline ITEMS & DEFINITION & 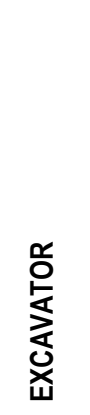 & 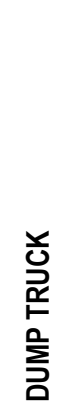 & 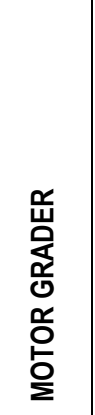 & 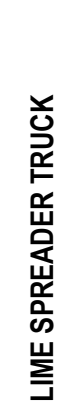 & 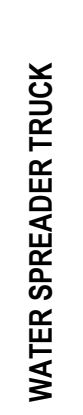 & 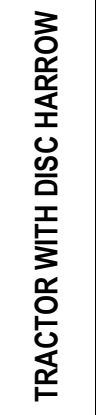 & 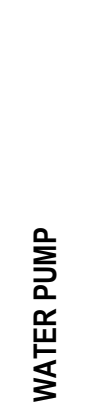 & 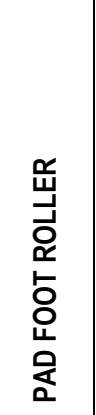 & 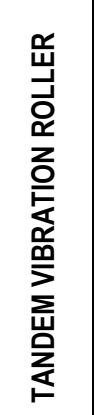 & 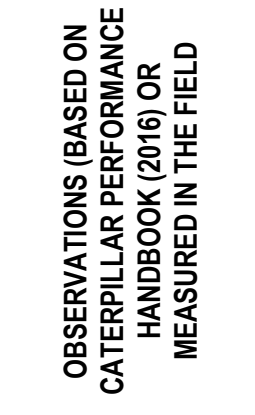 \\
\hline Capacity (Q) & $\begin{array}{l}\text { Receptacle capacity of } \\
\text { the machine (for } \\
\text { example excavator } \\
\text { buckets) }\end{array}$ & $1.5 \mathrm{~m}^{3}$ & $12 \mathrm{~m}^{3}$ & - & $\begin{array}{c}15,000 \\
\mathrm{~kg}\end{array}$ & $\begin{array}{l}18,000 \\
\text { Its }\end{array}$ & - & $\begin{array}{l}50,000 \\
\text { Its }\end{array}$ & - & - & Supplier information \\
\hline $\begin{array}{l}\text { Load factor } \\
\text { (Lf) }\end{array}$ & $\begin{array}{l}\text { Measured capacity / } \\
\text { Nominal capacity ratio }\end{array}$ & 0.85 & 0.85 & - & - & - & - & - & - & - & $\begin{array}{l}\text { Supplier information } \\
\text { and company's } \\
\text { experience }\end{array}$ \\
\hline $\begin{array}{l}\text { Layer } \\
\text { thickness }(e)\end{array}$ & $\begin{array}{l}\text { Thickness of the treated } \\
\text { and compacted layer }\end{array}$ & - & - & $0.20 \mathrm{~m}$ & - & - & $0.20 \mathrm{~m}$ & - & $0.20 \mathrm{~m}$ & $0.20 \mathrm{~m}$ & $\begin{array}{l}\text { Used in field to } \\
\text { guarantee compaction } \\
\text { (Company's } \\
\text { experience) } \\
\end{array}$ \\
\hline $\begin{array}{l}\text { Efficiency } \\
\text { ratio }\left(E_{f}\right)\end{array}$ & $\begin{array}{l}\text { Ratio between time } \\
\text { spent using the machine } \\
\text { and the time it is } \\
\text { available. }\end{array}$ & 0.85 & 0.75 & 0.75 & 0.75 & 0.75 & 0.75 & 0.75 & 0.75 & 0.75 & $\begin{array}{l}\text { In order to cover } \\
\text { machine-idle time } \\
\text { (Company's } \\
\text { experience) }\end{array}$ \\
\hline $\begin{array}{l}\text { Working } \\
\text { length }\left(A_{w}\right)\end{array}$ & $\begin{array}{l}\text { Difference between the } \\
\text { operation length and the } \\
\text { overlap length }\end{array}$ & - & - & $3.20 \mathrm{~m}$ & - & - & $2.35 \mathrm{~m}$ & - & $1.74 \mathrm{~m}$ & $1.93 \mathrm{~m}$ & $\begin{array}{l}\text { Depends on the } \\
\text { machine receptor } \\
\text { length (supplier } \\
\text { information) and the } \\
\text { working road lane } \\
\text { length ( } 6.4 \mathrm{~m} \text { in two } \\
\text { lanes) }\end{array}$ \\
\hline $\begin{array}{l}\text { Number of } \\
\text { passes }(n)\end{array}$ & Number of passes & - & - & 30 & - & - & 10 & - & 6 & 2 & $\begin{array}{l}\text { Selected by an } \\
\text { experimental section to } \\
\text { obtain the desire } \\
\text { mixture, }\end{array}$ \\
\hline $\begin{array}{l}\text { Total cycle } \\
\text { time }\left(T_{i}\right)\end{array}$ & $\begin{array}{l}\text { Time for loading, } \\
\text { unloading, maneuvering } \\
\text { operations (in excavator) } \\
\text { and material } \\
\text { transportation (in trucks). }\end{array}$ & $\begin{array}{l}0.45 \\
\min \end{array}$ & $\begin{array}{l}19.63 \\
\min \end{array}$ & - & $\begin{array}{l}93.14 \\
\min \end{array}$ & $\begin{array}{l}49.56 \\
\min \end{array}$ & - & $\begin{array}{l}49.56 \\
\min \end{array}$ & - & - & $\begin{array}{l}\text { Depends on work } \\
\text { conditions for } \\
\text { excavator and mean } \\
\text { transport distance and } \\
\text { speed for trucks } \\
\text { (Company's } \\
\text { experience) } \\
\end{array}$ \\
\hline $\begin{array}{l}\text { Average } \\
\text { speed }\left(V_{e}\right)\end{array}$ & Average speed & - & $\begin{array}{l}14.69 \\
\mathrm{~km} / \mathrm{h}\end{array}$ & $\begin{array}{l}11.25 \\
\mathrm{~km} / \mathrm{h}\end{array}$ & - & - & $8 \mathrm{~km} / \mathrm{h}$ & & $\begin{array}{c}4.5 \\
\mathrm{~km} / \mathrm{h}\end{array}$ & $3 \mathrm{~km} / \mathrm{h}$ & $\begin{array}{l}\text { Company's experience } \\
\text { (or supplier estimation) }\end{array}$ \\
\hline
\end{tabular}


619

620

Table 5 - Cured strength (28 days) requirements for soil-lime structural layers (modified from Thompson 1970).

\begin{tabular}{|c|c|c|}
\hline LAYER TYPE & NO FREEZE-THAW ACTIVITY & FREEZE-THAW* ZONE \\
\hline Base & $1,034 \mathrm{kPa}(150 \mathrm{psi})$ & $1,379 \mathrm{kPa}(200 \mathrm{psi})$ \\
Subbase & $689 \mathrm{kPa}(150 \mathrm{psi})$ & $1,034 \mathrm{kPa}(150 \mathrm{psi})$ \\
\hline
\end{tabular}

* Use these criteria if F-T cycles will occur in the structural layer. It is possible to be in a mild F-T area and not experience F-T cycles in the subbase or base layer. 
(a)

\begin{tabular}{|c|c|c|}
\hline \multirow{3}{*}{$\begin{array}{l}q_{u} \\
(\mathrm{kPa})\end{array}$} & 7 days & $1.02 \times 10^{8}\left[\eta / L_{i v} 0.16\right]^{-3.40}$ \\
\hline & 28 days & $1.42 \times 10^{8}\left[\eta / \mathrm{Liv}_{\mathrm{iv}}^{0.16}\right]^{-3.40}$ \\
\hline & 60 days & $1.80 \times 10^{8}\left[\eta / \mathrm{Liv}^{0.16}\right]^{-3.40}$ \\
\hline \multirow{3}{*}{$\begin{array}{l}q_{t} \\
(\mathrm{kPa})\end{array}$} & 7 days & $1.31 \times 10^{7}\left[\eta / \mathrm{Liv}^{0.16}\right]^{-3.40}$ \\
\hline & 28 days & $1.87 \times 10^{7}\left[\eta / L_{i v} 0.16\right]^{-3.40}$ \\
\hline & 60 days & $2.56 \times 10^{7}\left[\eta / L_{i v} 0.16\right]^{-3.40}$ \\
\hline \multirow{3}{*}{$\begin{array}{l}\mathrm{G}_{0} \\
(\mathrm{MPa})\end{array}$} & 7 days & $1.04 \times 10^{7}\left[\eta / L_{i v} 0.16\right]^{-2.60}$ \\
\hline & 28 days & $1.14 \times 10^{7}\left[\eta / \mathrm{Liv}_{\mathrm{iv}}{ }^{0.16}\right]^{-2.60}$ \\
\hline & 60 days & $1.57 \times 10^{7}\left[\eta / \mathrm{Liv}_{\mathrm{iv}}{ }^{0.16}\right]^{-2.60}$ \\
\hline
\end{tabular}

(b)

\begin{tabular}{|c|c|c|}
\hline \multirow{4}{*}{$\begin{array}{l}\text { Cost } \\
\text { (US\$) }\end{array}$} & Line $L_{3}$ & $35.75-0.44\left[\eta / \mathrm{Liv}_{\mathrm{iv}}^{0.16}\right]$ \\
\hline & Line $\mathrm{L}_{7}$ & $54.56-0.68\left[\eta / L_{i v} 0.16\right]$ \\
\hline & Line $\gamma_{19}$ & $140.46-4.33\left[\eta / \mathrm{Liv}^{0.16}\right]$ \\
\hline & Line $\gamma_{16}$ & $123.53-2.77\left[\eta / L_{i v}^{0.16}\right]$ \\
\hline \multirow{4}{*}{$\begin{array}{l}\text { Embodied Energy } \\
\text { (MJ) }\end{array}$} & Line $L_{3}$ & $722.59-7.27\left[\eta / L_{i v}{ }^{0.16}\right]$ \\
\hline & Line L7 & $1490.5-17.26\left[\eta / L_{i v}{ }^{0.16}\right]$ \\
\hline & Line $\gamma_{19}$ & $4896.4-162.52\left[\eta / \mathrm{Liv}^{0}{ }^{0.16}\right]$ \\
\hline & Line $\gamma_{16}$ & $4171.3-98.97\left[\eta / L_{i v}{ }^{0.16}\right]$ \\
\hline \multirow{4}{*}{$\begin{array}{l}\text { Global Warming } \\
\left(\mathrm{CO}_{2}\right)\end{array}$} & Line $L_{3}$ & $85.26-0.88\left[\eta / L_{i v}{ }^{0.16}\right]$ \\
\hline & Line L7 & $181.9-2.13\left[\eta / L_{i v} 0.16\right]$ \\
\hline & Line $\gamma_{19}$ & $611.26-20.44\left[\eta / \mathrm{Liv}^{0.16}\right]$ \\
\hline & Line $\gamma_{16}$ & $520.44-12.45\left[\eta / L_{i v}{ }^{0.16}\right]$ \\
\hline \multirow{4}{*}{$\begin{array}{l}\text { Photochemical } \\
\text { Oxidation } \\
\text { (kg of } \mathrm{C}_{2} \mathrm{H}_{2} \text {-eq.) }\end{array}$} & Line $\mathrm{L}_{3}$ & $0.0133-0.0001\left[\eta / L_{i v} 0.16\right]$ \\
\hline & Line $\mathrm{L}_{7}$ & $0.0281-0.0003\left[\eta / \mathrm{Liv}^{0.16}\right]$ \\
\hline & Line $\gamma_{19}$ & $0.0942-0.0031\left[\eta / L_{i v}^{0.16}\right]$ \\
\hline & Line $\gamma_{16}$ & $0.0802-0.0019\left[\eta / L_{i v} 0.16\right]$ \\
\hline
\end{tabular}


Figure 1 - Generic Unitary Cost Calculation sheet.

Figure 2 - Unitary Cost Calculation sheet for blend D5.

Figure 4 - Decision-making model for optimal dosages: (a) $G_{0} \times \eta / L_{i v}{ }^{0.16}$, (b) $q_{t} \times \eta / L_{i v}{ }^{0.16}$, (c) $q_{u} x \eta / L_{i v}^{0.16}$, (d) Cost $x \eta / L_{i v}^{0.16}$, (e) Embodied Energy $x \eta / L_{i v}{ }^{0.16}$, (f) Global Warming $\mathrm{x} \eta / \mathrm{Liv}^{0.16}$, and $(\mathrm{g})$ Photochemical Oxidation $\mathrm{x} \eta / \mathrm{L}_{i v} 0.16$.

Figure 3 - Cost and environmental impacts for different blends dosages (Table 1). (a) Cost in US\$ $/ \mathrm{m}^{3}$, (b) Embodied Energy in $\mathrm{MJ} / \mathrm{m}^{3}$, (c) Carbon Dioxide Emission in $\mathrm{kg}$ of $\mathrm{CO}_{2-}$ eq. $/ \mathrm{m}^{3}$ and (d) Photochemical Oxidation in $\mathrm{kg}$ of $\mathrm{C}_{2} \mathrm{H}_{4}$-eq. $/ \mathrm{m}^{3}$.

\section{.}




\begin{tabular}{|c|c|c|c|c|c|}
\hline 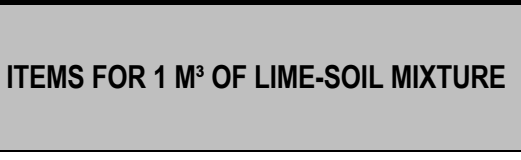 & $\begin{array}{l}\text { Column (I) } \\
\text { [Quantity] }\end{array}$ & $\begin{array}{l}\text { Column (II) } \\
\text { [Consumption] }\end{array}$ & $\begin{array}{l}\text { Column (III) } \\
\text { [Productivity] }\end{array}$ & $\begin{array}{l}\text { Column (IV) } \\
\text { [Unitary Cost] }\end{array}$ & $\begin{array}{c}\text { TOTAL } \\
\text { COSTS PER } \\
\text { UNIT } \\
{\left[U S \$ / M^{3}\right]} \\
\end{array}$ \\
\hline 1. Lime production & $1.05 \mathrm{~kg} / \mathrm{kg}$ & Variable A & & 0.14 US\$ $/ \mathrm{kg}$ & \\
\hline 2. Lime transportation & $1.05 \mathrm{~kg} / \mathrm{kg}$ & Variable A & & 0.07 US\$/kg & \\
\hline 3. Soil Extraction & $1 \mathrm{~m}^{3} / \mathrm{m}^{3}$ & Variable B & & $2.50 \cup S \$ / m^{3}$ & \\
\hline 3.1 Excavator & 1 & $0.01 \mathrm{~h} / \mathrm{m}^{3}$ & $100.00 \mathrm{~m} / \mathrm{h}$ & 96.46 US\$/h & 0.96 \\
\hline 3.2 Material cost & 1 & 1 & - & $1.50 \mathrm{US} \$ / \mathrm{m}^{3}$ & 1.50 \\
\hline 3.2 Construction worker & 1 & $0.01 \mathrm{~h} / \mathrm{m}^{3}$ & $100.00 \mathrm{~m}^{3} / \mathrm{h}$ & $3.53 \cup S \$ / m^{3}$ & 0.04 \\
\hline 4. Soil Transportation & $1 \mathrm{~m}^{3} / \mathrm{m}^{3}$ & Variable B & & $4.03 \mathrm{US} \$ / \mathrm{m}^{3}$ & \\
\hline 4.1 Dump truck & 4 & $0.032 \mathrm{~h} / \mathrm{m}^{3}$ & $31.25 \mathrm{~m}^{3} / \mathrm{h}$ & 31.50 US $\$ / h$ & 4.03 \\
\hline \multicolumn{6}{|l|}{ 5.1 Mixing lime-soil } \\
\hline 5.1.1 Motor grader & 1 & $1 /\left(64.00 \mathrm{~m}^{3} / \mathrm{h}\right)$ & $64.00 \mathrm{~m}^{3} / \mathrm{h}$ & 63.97 US\$/h & 1.00 \\
\hline 5.1.2 Lime spreader & 1 & 1/(Variable C) & Variable C & 35.20 US\$/h & \\
\hline 5.1.3 Road cold recycler machine & 1 & $1 /\left(200 \mathrm{~m}^{3} / \mathrm{h}\right)$ & $200.00 \mathrm{~m}^{3} / \mathrm{h}$ & 118.04 US\$/h & 0.59 \\
\hline 5.1.4 Water spreader truck & 1 & 1/(Variable D) & Variable D & 36.14 US\$/h & \\
\hline 5.1.5 Tractor with steel blade disks & 1 & 1/(Variable E) & Variable E & 34.85 US\$/h & \\
\hline 5.1.6 Water pump & 1 & 1/(Variable F) & Variable F & 14.16 US\$/h & \\
\hline 5.1.7 Construction worker & 2 & $1 /\left(64.00 \mathrm{~m}^{3} / \mathrm{h}\right)$ & $64.00 \mathrm{~m}^{3} / \mathrm{h}$ & $3.53 \mathrm{US} \$ / \mathrm{m}^{3}$ & 0.11 \\
\hline \multicolumn{6}{|l|}{ 5.2. Compaction and Consolidation } \\
\hline 5.2.1 Pad-foot roller & 1 & $1 /$ Variable $\mathrm{G}$ & Variable G & 39.81 US\$/h & \\
\hline 5.2.2 Tandem Vibratory Rollers & 1 & 1/Nariable $\mathrm{H}$ & Variable $\mathrm{H}$ & 34.36 US $\$ / h$ & \\
\hline TOTAL COSTS PER M ${ }^{3}$ & & & & & \\
\hline
\end{tabular}




\begin{tabular}{|c|c|c|c|c|c|}
\hline ITEMS FOR $1 \mathrm{M}^{3}$ OF LIME-SOIL MIXTURE & $\begin{array}{l}\text { Column (I) } \\
\text { [Quantity] }\end{array}$ & $\begin{array}{c}\text { Column (II) } \\
\text { [Consumption] }\end{array}$ & $\begin{array}{l}\text { Column (III) } \\
\text { [Productivity] }\end{array}$ & $\begin{array}{l}\text { Column (IV) } \\
\text { [Unitary Cost] }\end{array}$ & $\begin{array}{c}\text { TOTAL COSTS } \\
\text { PER UNIT } \\
{\left[U S \$ / M^{3}\right]}\end{array}$ \\
\hline 1. Lime production & $1.05 \mathrm{~kg} / \mathrm{kg}$ & $83.33 \mathrm{Kg} / \mathrm{m}^{3}$ & & 0.14 US\$/kg & 12.25 \\
\hline 2. Lime transportation & $1.05 \mathrm{~kg} / \mathrm{kg}$ & $83.33 \mathrm{Kg} / \mathrm{m}^{3}$ & & 0.07 US\$/kg & 6.13 \\
\hline 3. Soil Extraction & $1.00 \mathrm{~m}^{3} / \mathrm{m}^{3}$ & $1.08 \mathrm{~m}^{3} / \mathrm{m}^{3}$ & & 2.50 US $\$ / \mathrm{m}^{3}$ & 2.70 \\
\hline 3.1 Excavator & 1 & $0.01 \mathrm{~h} / \mathrm{m}^{3}$ & $100.00 \mathrm{~m}^{3} / \mathrm{h}$ & 96.46 US\$/h & 0.96 \\
\hline 3.2 Material cost & 1 & 1 & - & 1.50 US $\$ / \mathrm{m}^{3}$ & 1.50 \\
\hline 3.2 Construction worker & 1 & $0.01 \mathrm{~h} / \mathrm{m}^{3}$ & $100.00 \mathrm{~m}^{3} / \mathrm{h}$ & 3.53 US\$ $/ \mathrm{m}^{3}$ & 0.04 \\
\hline 4. Soil Transportation & $1.00 \mathrm{~m}^{3} / \mathrm{m}^{3}$ & $1.08 \mathrm{~m}^{3} / \mathrm{m}^{3}$ & & 4.03 US\$ $/ \mathrm{m}^{3}$ & 4.36 \\
\hline 4.1 Dump truck & 4 & $0.032 \mathrm{~h} / \mathrm{m}^{3}$ & $31.25 \mathrm{~m}^{3} / \mathrm{h}$ & 31.50 US\$/h & 4.03 \\
\hline 5.1 Mixing lime-soil & & & & & 2.95 \\
\hline 5.1.1 Motor grader & 1 & $0.0156 \mathrm{~h} / \mathrm{m}^{3}$ & $63.95 \mathrm{~m}^{3} / \mathrm{h}$ & 63.97 US\$/h & 1.00 \\
\hline 5.1.2 Lime spreader & 1 & $0.0115 \mathrm{~h} / \mathrm{m}^{3}$ & $86.97 \mathrm{~m}^{3} / \mathrm{h}$ & 35.20 US\$/h & 0.40 \\
\hline 5.1.3 Road cold recycler machine & 1 & $0.005 \mathrm{~h} / \mathrm{m}^{3}$ & $200.00 \mathrm{~m}^{3} / \mathrm{h}$ & 118.04 US\$/h & 0.59 \\
\hline 5.1.4 Water spreader truck & 1 & $0.014 \mathrm{~h} / \mathrm{m}^{3}$ & $71.83 \mathrm{~m}^{3} / \mathrm{h}$ & 36.14 US\$/h & 0.50 \\
\hline 5.1.5 Tractor with steel blade disks & 1 & $0.008 \mathrm{~h} / \mathrm{m}^{3}$ & $124.89 \mathrm{~m}^{3} / \mathrm{h}$ & 34.85 US\$/h & 0.28 \\
\hline 5.1.6 Water pump & 1 & $0.005 \mathrm{~h} / \mathrm{m}^{3}$ & $199.54 \mathrm{~m}^{3} / \mathrm{h}$ & 14.16 US\$/h & 0.07 \\
\hline 5.1.7 Construction worker & 2 & $0.016 \mathrm{~h} / \mathrm{m}^{3}$ & $64.00 \mathrm{~m}^{3} / \mathrm{h}$ & 3.53 US\$ $/ \mathrm{m}^{3}$ & 0.11 \\
\hline 5.2. Compaction and Consolidation & & & & & 0.38 \\
\hline 5.2.1 Pad-foot roller & 1 & $0.007 \mathrm{~h} / \mathrm{m}^{3}$ & $136.47 \mathrm{~m}^{3} / \mathrm{h}$ & 39.81 US\$/h & 0.29 \\
\hline 5.2.2 Tandem Vibratory Rollers & 1 & $0.003 \mathrm{~h} / \mathrm{m}^{3}$ & $384.62 \mathrm{~m}^{3} / \mathrm{h}$ & 34.36 US\$/h & 0.09 \\
\hline TOTAL COSTS PER M ${ }^{3}$ & & & & & 28.77 \\
\hline
\end{tabular}




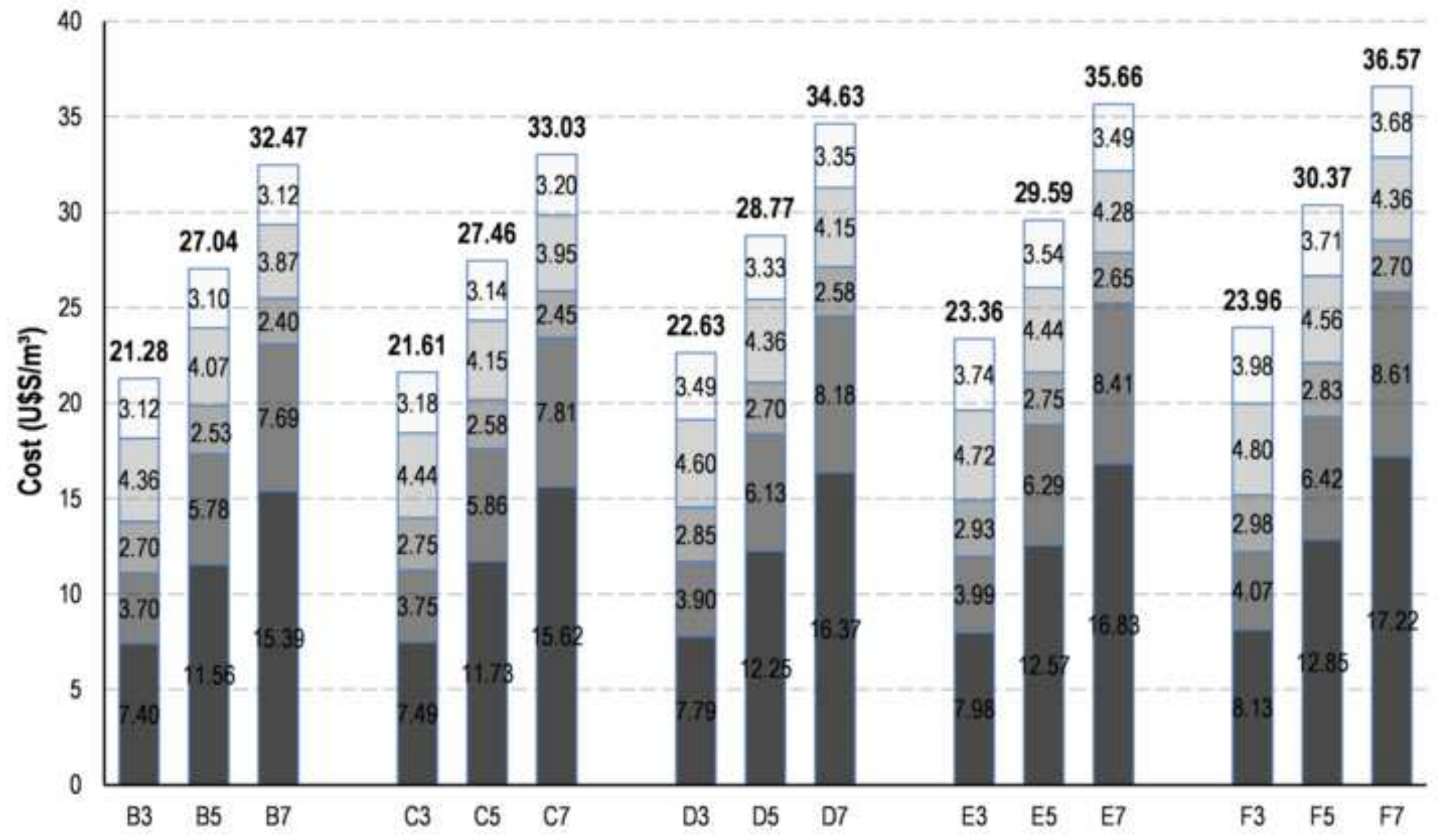

$=$ Lime Production (1) = Lime Transportation (2) $=$ Soil Extraction (3) $\square$ Soil Transportation (4) $\square$ Blends Production (5) 


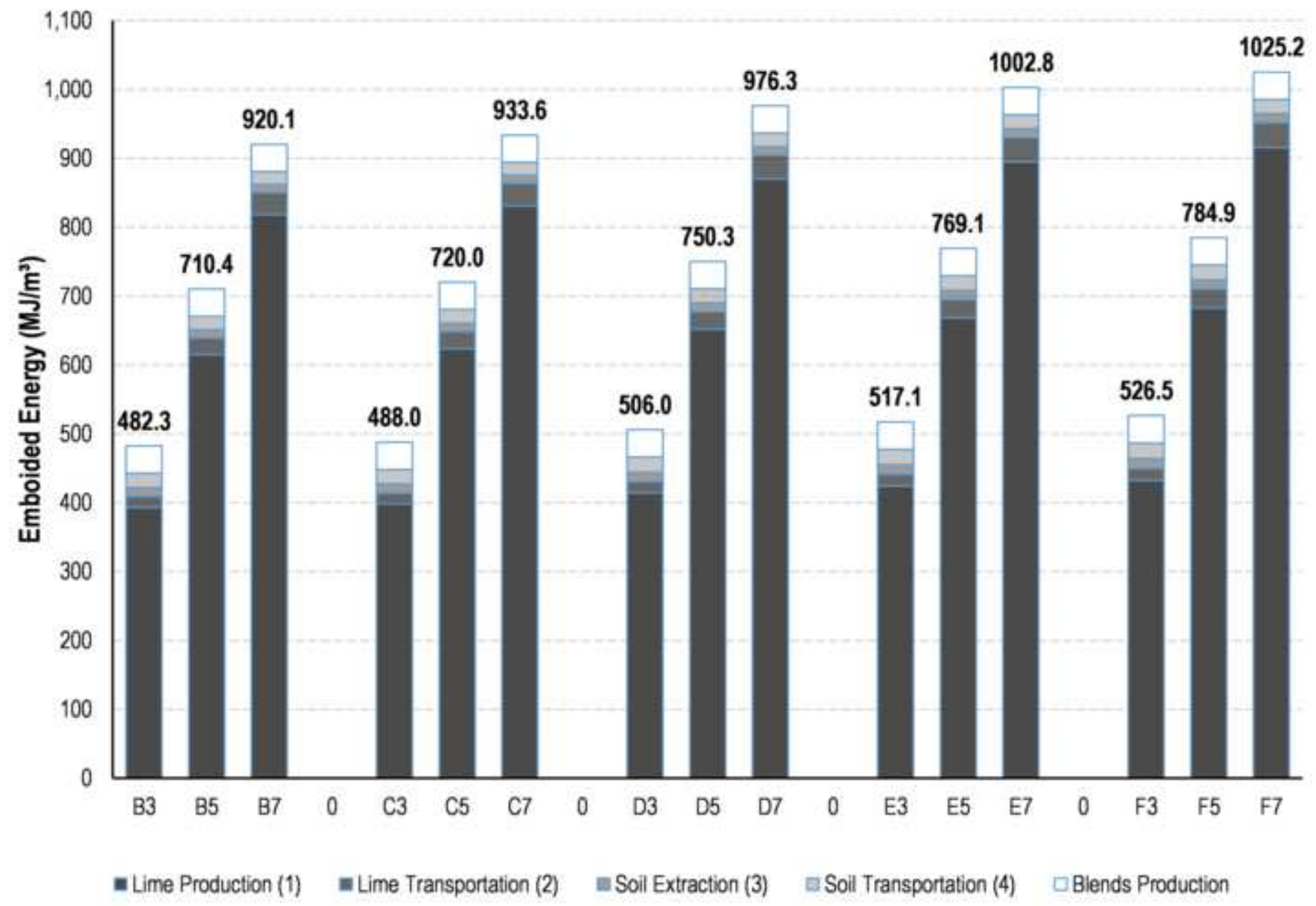




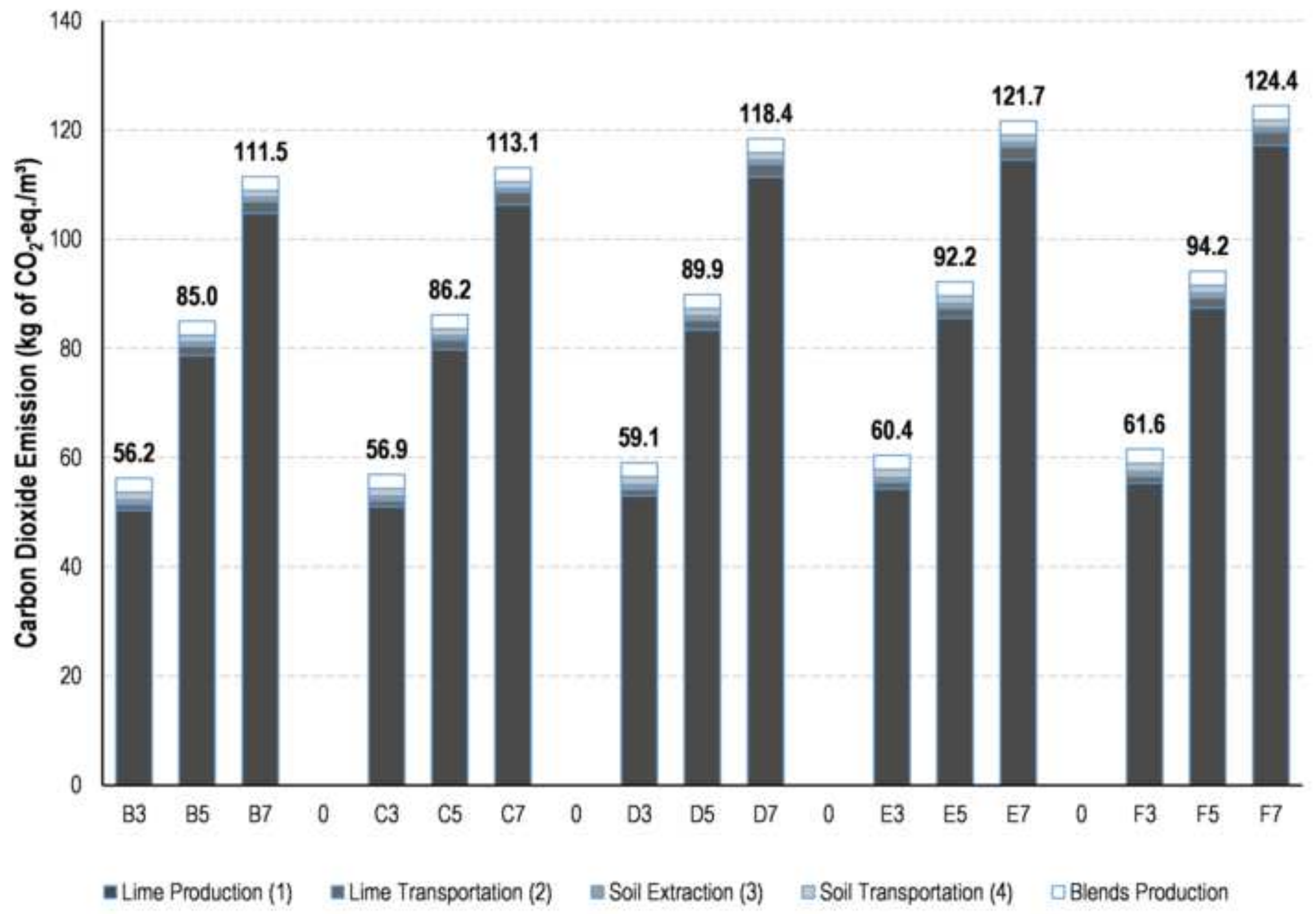




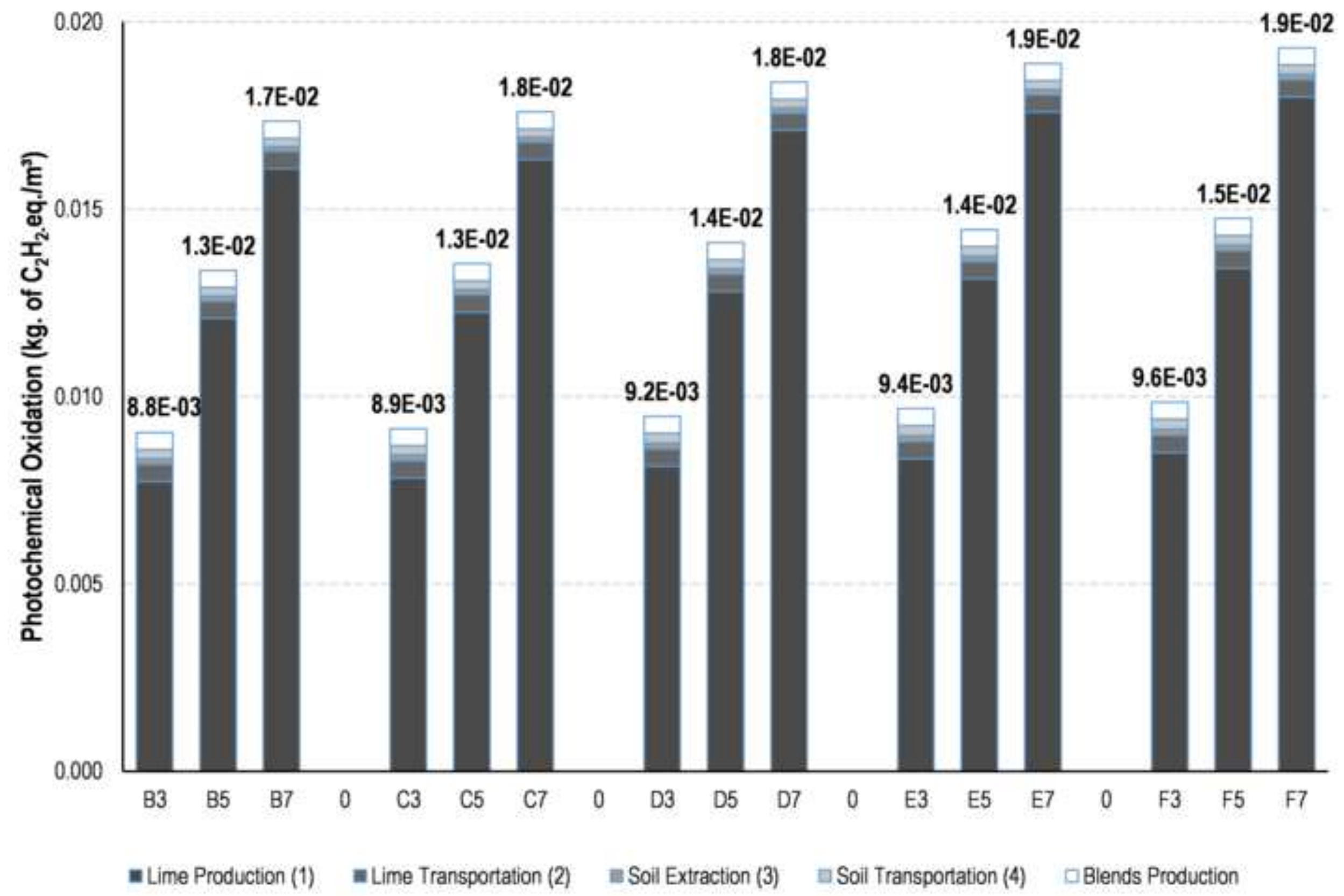



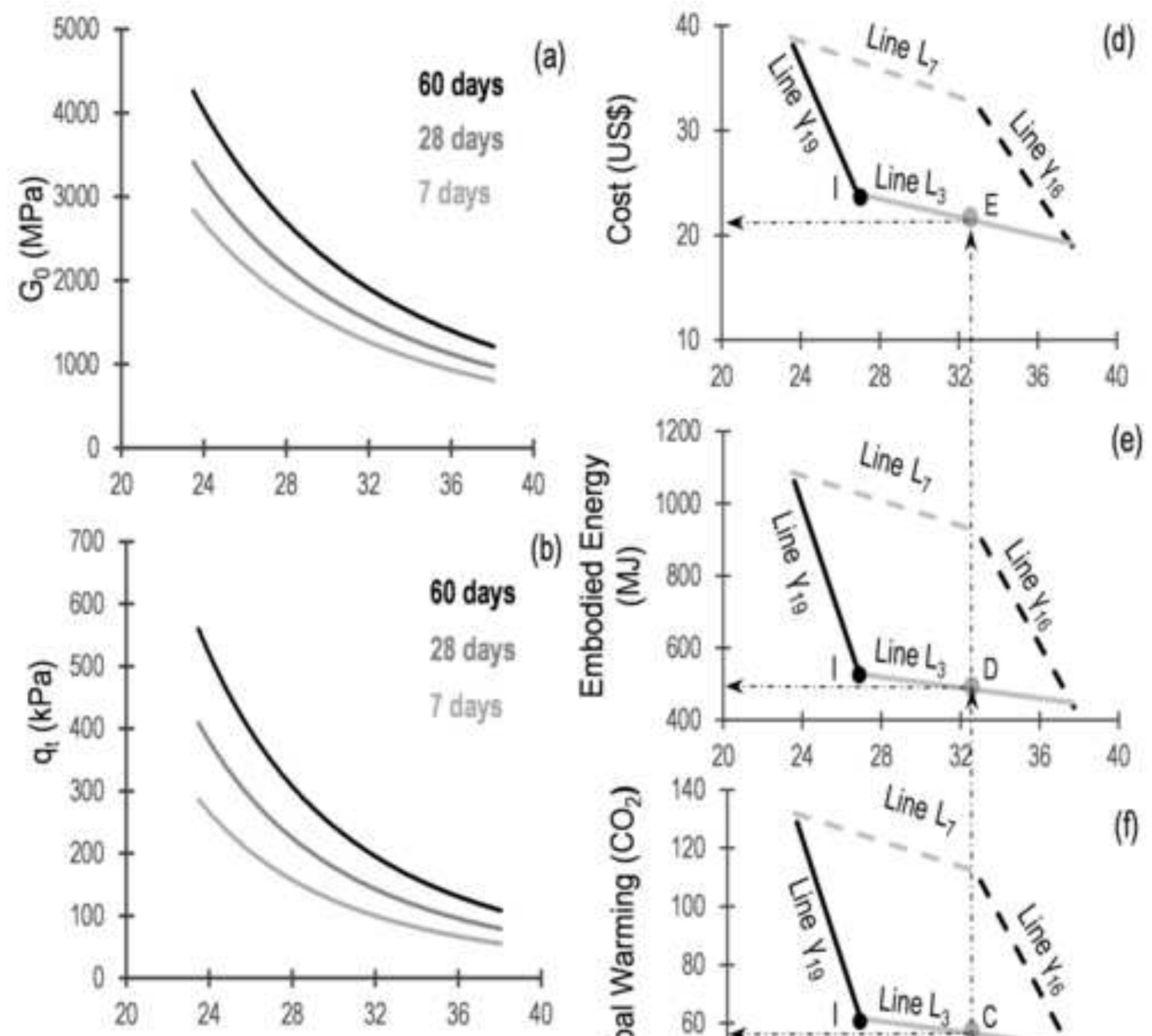

(b)
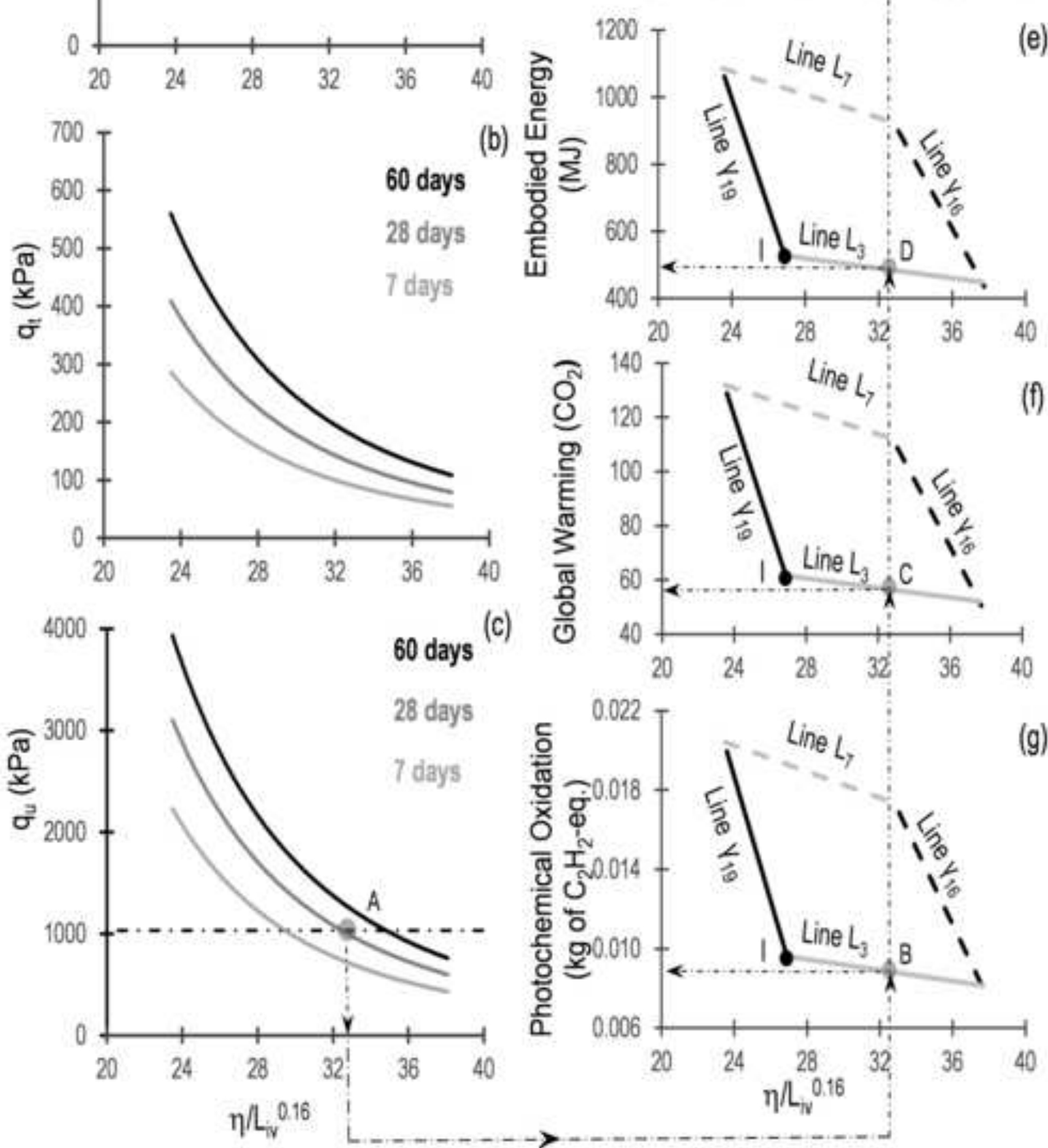

(c)
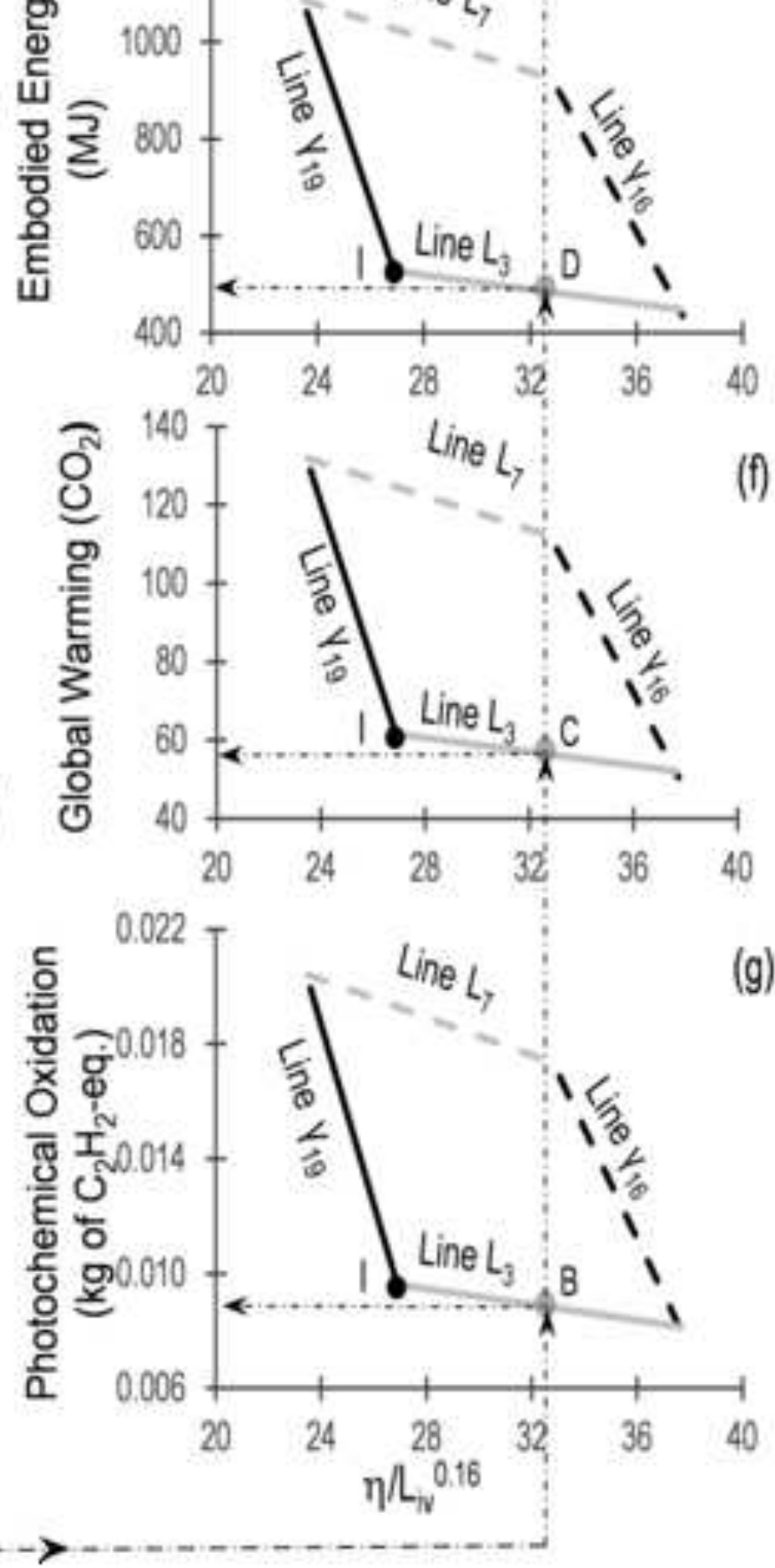


\section{RESPONSE TO THE REVIEWERS COMMENTS}

Ref.: Ms. No. MTENG-10490

Title: A Decision-Making Model for Soil Stabilization: Minimizing Cost and Environmental Impacts

Authors: Cecília Gravina da Rocha; Eduardo José Bittar Marin; Rubén Alejandro Quiñónez Samaniego; Nilo Cesar Consoli

Reviewers' comments:

AE: This paper has been reviewed by 3 experts in this field of study. The majority of the reviewers have recommended that the paper requires significant revisions. Comments of the reviewers are provided for the authors to review and address, should they wish to revise the paper.

The authors have responded all questions raised by the reviewers.

Reviewer \# 1: This study performed sustainability analysis of chemical soil stabilization using different binders with a focus on economic and environmental viewpoints. The paper reads good and could potentially provide new insight into how to maximize economical, environmental and engineering performance benefits in ground improvement practice. I do not have specific comments on technical aspects of this paper. As an optional suggestion, the authors may consider reformatting tables and figures in this paper, as it is sometimes difficult to get the key information.

The authors have enhanced the tables and the figures to improve understanding.

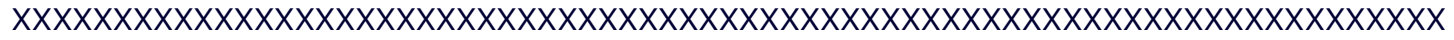

Reviewer \#2: As a technical note the paper talks a novel decision making model for stabilisation. Overall it is a decent paper however, writing needs improvement.

\section{$\underline{2.1 \text { Abstract needs to provide a bit more details of findings. }}$}

The Abstract was rewritten in order to provide more details about findings (see below):

"Studies have examined the environmental impacts of soil stabilization, however the costs of distinct dosages for such technique remain unexplored. Indeed, it is not yet clear whether there is a trade-off between cost and environmental impacts for soil stabilization dosages. This technical note seeks to address this gap by performing an economic analysis of three dosage strategies (high binder/low dry unit weight, medium binder/medium dry unit weight, low binder/high dry unit weight) considering five values for porosity-binder index and strength and stiffness as performance parameters. Such results were then combined with environmental impact data to create a decision-making model for optimal dosages considering the economic and environmental dimensions of sustainability. An example for road base $\left(q_{u}=1,034 \mathrm{kPa}\right)$ is presented here to illustrate how the model can be applied in real-world projects. Such $q_{u}$ corresponds to a porositybinder index of 32.44 which can be attained by different combinations of dry unit weight and binder content ranging, respectively, from 16 to $19 \mathrm{kN} / \mathrm{m}^{3}$ to 3 to $7 \%$. Using the proposed model, the dosage with minimal cost and environmental impacts could be determined: lime content of $3 \%$ and dry unit weight of $17.44 \mathrm{kN} / \mathrm{m}^{3}$. Binder was found to be the main contributor for cost and environmental impacts, indicating that dosages with minimal binder content and maximum dry unit weight should be preferred. The findings presented here suggest that there is not a trade-off between environmental and economic pillars and dosages with minimal cost and impacts can be created." 


\subsection{Tables are too complex to digest and they don't follow the same font and pattern.}

Tables were enhanced in order to reduce complexity. The Tables are now using the same font.

\subsection{Figure 3 is difficult to understand.}

Figure 3 was improved.

\subsection{The validation of the model is missing which is a key part in such studies.}

Based in the concept that the study is using real data from soil tests, equations based in field experience, performance and unitary costs from the company that built the equipments, it is acceptable to assume that the results and analysis are correct. Future research is being planned about studying a real case with measurements of costs, but it is out of the scope of this technical note.

However, the authors have added to the manuscript an important point about generalization of the model developed herein (see below):

"In terms of generalization of the proposed model and its applicability to other blends, it is worth highlighting that the $\left(\eta / L_{i v}{ }^{a}\right)^{\mathrm{b}}$ index with exponent "a" varying from 0.12 to 0.16 and exponent " $b$ " varying from -4.1 to -3.4 has been found to be a good predictor of strength, among other properties for several blends for soil stabilization. These include clayey sand-lime blends (Consoli et al. 2014), clay-lime (Consoli et al. 2016b), sulfated clay-lime (Consoli et al. 2017) and silt-lime (Consoli et al. 2017). Also, the ranges for density and binder content are similar to the ones studied here: density varying from $11 \mathrm{kN} / \mathrm{m}^{3}$ to $19 \mathrm{kN} / \mathrm{m}^{3}$ and lime content varying from $3 \%$ to $9 \%$. As a result, the quadrilateral shape outlining all combinations of dry unit weight and binder contents presented in Figs. 4 and which provides the basis for the proposed decision-making model also applies to these other blends. Clearly, the dimension and steepness of the four lines forming the quadrilateral may vary depending on the particular properties of the blends, the range of values for density and binder content examined, the costs and environmental impacts of the studied materials, etc. However, the overall shape and also associated decision-making process apply. The latter can be summarized as follows: (1) Determine the $\eta / L_{i v}{ }^{a}$ value for the required performance $\left(q_{u}, q_{t}, G_{0}\right.$, etc.). (2) Check if such $\eta / L_{i v}{ }^{a}$ value falls in the quadrilateral line for minimal binder content ( $L_{3}$ in the example discussed here). (3) If that is the case, determine the required density (for the minimum lime content) to attain the $\eta / L_{i v}{ }^{a}$ value. (4) If that is not the case, namely, the value falls in the quadrilateral line for maximum density ( $\gamma_{19}$ in the example discussed here), determine the required binder content (for the maximum density) to attain the $\eta / L_{i v}{ }^{a}$ value."

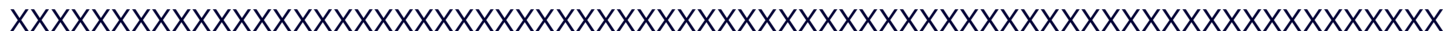

Reviewer \#3: This manuscript presents the results of a study to propose a model for choosing the right binder content and density in stabilization projects while minimizing economic and environmental impacts. The study is well organized and the topic is interesting. The manuscript is meaningful in respect of showing detailed analytical approach. Therefore, the findings shown in this manuscript are expected to contribute to the development of civil engineering, and are also interesting to the readers of the Journal of Materials in Civil Engineering. Authors should provide additional explanations and improve the manuscript before this paper could be published though. The comments to address are as follows:

3.1 Although the study focuses on only one type of clay and lime, as the binder, it would be interesting, to readers, to discuss the use of other binders, such as cement or geopolymers, for stabilizing clay in the literature review section. There has been several interesting studies including the following:

* Yaghoubi, M.; Arulrajah, A.; Disfani, M. M.; Horpibulsuk, S.; Darmawan, S. and Wang, J.; 2019. Impact of field conditions on the strength development of a geopolymer stabilized marine clay, Applied Clay Science, Vol. 167, pp. 33-42. 
* Arulrajah, A.; Yaghoubi, M.; Disfani, Mahdi M. M.; Horpibulsuk, S; Bo, M. W. and Leong, M.; 2018. Evaluation of fly ash- and slag-based geopolymers for the improvement of a soft marine clay by deep soil mixing, Soils and Foundations, Vol. 58, No. 6, pp. 1358-1370.

* Al-Taie, A.; Disfani, M. M.; Evans, R. and Arulrajah, A.; 2019. Collapse and swell of lime stabilized expansive clays in void ratio-moisture ratio-net stress space, International Journal of Geomechanics, Vol. 19, No. 9, article no. 04019105.

* Donrak, J.; Horpibulsuk, S.; Arulrajah, A.; Kou, H.; Chinkulkijniwat, A. and Hoy, M.; 2020. Wetting-drying cycles durability of cement stabilised marginal lateritic soil/melamine debris blends for pavement applications, Road Materials and Pavement Design, Vol. 21, No. 2, pp. 500-518.

The authors have enhanced the Introduction (see below):

"Soil stabilization, entailing physical (soil compaction) and/or chemical (addition of small amounts of a binder - such as lime, pozzolan-lime, Portland cement or geopolymers) techniques, can be used to enhance the mechanical performance of soils (e.g. Ingles and Metcalf 1972; Consoli et al. 2012, 2018a, 2018b, 2019a, 2019b, 2020a, 2020b; Arulrajah et al. 2018; Al-Taie et al. 2019; Yaghoubi et al. 2019; Donrak et al. 2020)."

3.2 The authors need to discuss the effect(s) of properties of soil such as plasticity. In this regard, it would be beneficial to present the properties of the studied clay.

The authors have added the following paragraph to attend to the Reviewer suggestion (see below):

"The soil studied herein is classified as a lean clay (CL) according to ASTM D 2487 (ASTM 2017). Its total dissolved salts (TDS) reach $15.2 \mathrm{mEq} / \mathrm{L}$, with a percentage of sodium (PS) of $91.4 \%$. According to Sherard et al. (1976), a relationship of pore water salts and dispersion of compacted soil samples measured in laboratory with a pinhole test suggested that soils with TDS superior to $1.0 \mathrm{mEq} / \mathrm{L}$ and PS higher than $60 \%$, which encloses presently studied clay, might be considered dispersive. The main physical properties of the studied dispersive clay are: $43 \%$ liquid limit, $24 \%$ plastic index, 2.74 specific gravity, $34 \%$ clay (diameter $<0.002-\mathrm{mm}), 59 \%$ silt $(0.002-$ $\mathrm{mm}<$ diameter $<0.075-\mathrm{mm})$ and $7 \%$ fine sand $(0.075-\mathrm{mm}<$ diameter $<0.425-\mathrm{mm})$, the mean particle diameter is $0.005-\mathrm{mm}$, and the maximum dry unit weight and the optimum moisture content for modified Proctor compaction effort are $19.0 \mathrm{kN} / \mathrm{m}^{3}$ and $13 \%$, respectively. Consoli et al. (2016a) have shown that independently of the dry unit weights considered, the studied clay has shown to change from moderately dispersive when no lime is added to nondispersive for amounts of lime insertion of 3\% or above (the lime range studied herein varied from 3\% to $7 \%$ ). The plastic index of the soil reduced from $24 \%$ (without lime addition) to about $15 \%$ (soil with $3 \%$ to $7 \%$ of lime) due to lime addition. A dolomitic hydrated lime with a specific gravity of 2.60 was used."

\subsection{Equations 10 and 11:}

- The parameters density and unit weight are not the same. It should be checked throughout the manuscript;

- ys is not defined; and

- It would be more consistent to use ydL for lime dry unit weight instead of YSL.

Equations (10 and (11) and definitions were corrected in the manuscript (see below):

$\eta=100\left[1-\frac{\gamma_{d}}{1+\frac{L}{100}}\left(\frac{1}{\gamma_{s S}}+\frac{L}{100 \times \gamma_{s_{L}}}\right)\right]$ 
$L_{i v}=100\left(\frac{\gamma_{d}}{1+\frac{L}{100}}\right)\left(\frac{L}{100 \times \gamma_{s_{L}}}\right)$

"where $\gamma_{d}$ is the dry density of the blend, $\mathrm{L}$ is the lime content (expressed in relation to mass of dry soil), and $\gamma_{s_{S}}$ and $\gamma_{s_{L}}$ are the unit weight of solids of the soil and unit weight of solids of the lime, respectively."

3.4 The authors have used low, medium and high density and dosage in their study. However, it is not explained what the basis of low, medium and high is.

In order to explain the values used, the authors have added the following sentences to the manuscript (see below):

"The studied densities were defined according to the modified Proctor compaction test (ASTM D1557 2012) of soil-lime blends (using the $5 \%$ of lime as base). The modified Proctor compaction effort results for soil - $5 \%$ of lime (average value of lime in weight) blends indicated a maximum dry unit weight of $19 \mathrm{kN} / \mathrm{m}^{3}$ and the optimum moisture content of $13 \%$, the same values as for the soil compaction results without lime. So, the high-dry unit weight value was established as the maximum dry unit weight of $19 \mathrm{kN} / \mathrm{m}^{3}$ under modified Proctor compaction effort. The dry unit weight values of $17.5 \mathrm{kN} / \mathrm{m}^{3}$ and $16.0 \mathrm{kN} / \mathrm{m}^{3}$ were considered as medium and low densities. So, the studied dry unit weight values $\left(16,17.5\right.$ and $\left.19 \mathrm{kN} / \mathrm{m}^{3}\right)$ are seen to be attained by equipments that transfer low, medium, and high compaction energies to the soil. The moisture content of $13 \%$ was kept the same for all dry unit weights."

3.5 Unit weights of $16,17.5$ and $19 \mathrm{kN} / \mathrm{m}^{3}$ have been defined as low, medium and high unit weights. However, the unit weight values of mixtures, based on what the model has been proposed, are spread through this range. This needs more clarification. Also, it would be better to state from where the unit weight values are obtained.

In order to justify the dry unit weight values used, the authors have added the following sentences to the manuscript (see below):

"The studied densities were defined according to the modified Proctor compaction test (ASTM D1557 2012) of soil-lime blends (using the $5 \%$ of lime as base). The modified Proctor compaction effort results for soil - $5 \%$ of lime (average value of lime in weight) blends indicated a maximum dry unit weight of $19 \mathrm{kN} / \mathrm{m}^{3}$ and the optimum moisture content of $13 \%$, the same values as for the soil compaction results without lime. So, the high-dry unit weight value was established as the maximum dry unit weight of $19 \mathrm{kN} / \mathrm{m}^{3}$ under modified Proctor compaction effort. The dry unit weight values of $17.5 \mathrm{kN} / \mathrm{m}^{3}$ and $16.0 \mathrm{kN} / \mathrm{m}^{3}$ were considered as medium and low densities. So, the studied dry unit weight values $\left(16,17.5\right.$ and $\left.19 \mathrm{kN} / \mathrm{m}^{3}\right)$ are seen to be attained by equipments that transfer low, medium, and high compaction energies to the soil. The moisture content of $13 \%$ was kept the same for all dry unit weights."

\subsection{Line 178: what is the basis of multiplying Variable A by $5 \%$ ?}

The sentence has been enhanced (see below):

"The total costs for Lime Production (1) is the result of Variable A (Column II) multiplied by a 1.05 , which considers $100 \%$ of selected dosage of lime plus $5 \%$ of it to consider the possible loss of lime occurring during lime application (Column I) and by the lime unitary cost (Column IV)." 
Performance is referred to the expected functionality and structural response of the geo-material. According to Little (1998), lime can be used to improve the strength and performance of good quality to high quality aggregate bases. The stronger, stiffer and more stable (volumetrically) lime treated subgrade, subbase or base layers provide better protection for weak and deformation susceptible natural subgrades and better support of unbound aggregate bases and asphalt surfaces, thus enhancing their performance.

The engineering property associated with these performance characteristics are typically the unconfined compressive strength, the indirect tensile strength, the flexural strength and the California bearing ratio in some cases. More sophisticated tests such as resilient modulus test is the best characterization method for pavement layers and sub-layers materials. Nevertheless, all the engineering properties previously mentioned have shown correlations with the unconfined compressive strength which is a simpler unexpansive and well-known test.

\subsection{Figure 3: the vertical axes titles should be presented.}

Done as requested.

\subsection{Figures 4, 5 and 6: the porosity symbol is not clear.}

Figures 4, 5 and 6 were coupled in a unique new Figure 4.

3.10. Figure 5: what about binder content of $5 \%$ and dry unit weight of $17.5 \mathrm{kN} / \mathrm{m}^{3}$ ? Where do they fit on the curves?

Other binder content/dry unit weight combinations studied in this manuscript such as $5 \%$ lime and $\gamma_{d}=17.5 \mathrm{kN} / \mathrm{m}^{3}$ are inside the quadrilaterals showed in the model. For practical purposes, only boundary results are illustrated. Interpolation and even extrapolation of those lines can provide reasonable estimations of cost and environmental impacts as there are not significant differences among line inclination values. However, binder content/dry unit weight combinations are restricted by the minimum binder content to obtain suitable pozzolanic reactions ( $3 \%$ in this case represented by Line $L_{3}$ ) and the maximum dry unit weight achievable by applicable compaction-rollers energies $\left(19 \mathrm{kN} / \mathrm{m}^{3}\right.$ in this case represented by Line $\gamma_{19}$ ).

The new paragraphs are shown below:

"In this section, a graphical use of the decision-making model for optimal dosages is described. Figs. 4(a-g) show the decision-making model considering the economic and environmental pillars of sustainable development. In a first stage, the target value for the desired performance is determined, so the porosity-binder index $\left(\eta / L_{i v} 0.16\right)$ required for such performance is obtained. Several mixtures design and protocols can be found in the literature and the strength requirements for using lime stabilized solutions as structural layers in pavement systems vary considerably from agency to agency (Little 1998). In this example, the mixture design is defined by Thompson (1970) criteria showed in Table 5 for bases in no freeze-thaw activity on structural layer. Thus, 28 days of curing minimum strength of $1,034 \mathrm{kPa}$ in unconfined compressive strength is selected for the design of base layers. The porosity-binder index $\left(\eta / L_{i v}{ }^{0.16}\right)$ required for such performance is then 32.44 according to point A in Fig. 4(a). Moreover, in cases where more than one design parameter is required, other performance requirements such as tensile strength [Figure 4(b)], and initial shear modulus [Figure 4(c)] can be assessed for the design porositybinder index.

The porosity-binder index 32.44 (required for the compressive strength for the example considered) can be attained by different combinations of dry unit weight and binder contents as long as the base layer construction and compaction are possible. These combinations are represented by the quadrilaterals illustrated in Figs. $4(\mathrm{~d}-\mathrm{g})$ for economic and environmental impact evaluated in Fig. 3. Lines $L$ represent the variation of dry unit weights at constant lime contents ( $3 \%$ for $L_{3}$ and $7 \%$ for $L_{7}$ ) for different porosity-binder indexes whereas Lines $\gamma$ show the variation of lime contents at constant dry unit weights $\left(16 \mathrm{kN} / \mathrm{m}^{3}\right.$ for $\gamma_{16}$ and $19 \mathrm{kN} / \mathrm{m}^{3}$ for $\left.\gamma_{19}\right)$. Achievable dry unit weights are conditioned by the equipment to be used in field (compaction- 
rollers) whereas the minimum lime content ( $3 \%$ in this study) by methods such as the one described by Hilt and Davidson (1960). In this model, the maximum dry unit weight that can be achievable by typical compaction-rollers is limited by the value obtained in modified Proctor tests $\left(19 \mathrm{kN} / \mathrm{m}^{3}\right)$ and is represented by Lines $\gamma_{19}$ [Figs. $4(\mathrm{~d}-\mathrm{g})$ ]. The minimum lime content $(3 \%)$ is represented by Lines $L_{3}$ [Figures $4(d-g)$ ]. Therefore, optimum dosages (low binder/high dry unit weight) are captured by solid lines Line $L_{3}$ and Line $\gamma_{19}$ in Figs. 4(d-g), and their intersections (points I) depict the minimum porosity-binder index $\left(\eta / L_{i v} 0.16=26.94\right)$ available for optimum lowest binder $(L=3 \%) /$ highest dry unit weight $\left(\gamma_{d}=19 \mathrm{kN} / \mathrm{m}^{3}\right)$. For optimum porosity-binder index less than 26.94 an increment on lime content is inevitable (points will be on Lines $\gamma_{19}$ ).

Finally, the minimal values of cost and environmental impacts (embodied energy, carbon dioxide emission, or photochemical oxidation) obtained from these lines for the design $\eta / L_{i v}{ }^{0.16}=32.44$ are evident by dashed arrows in Figures $4(\mathrm{~d}-\mathrm{g})$. Thus, the optimum low binder/high dry unit weight combination from $\eta / L_{i v}{ }^{0.16}=32.44$ (for the compressive strength for the example considered) is composed by a lime content of $3 \%$ and dry unit weight of $17.44 \mathrm{kN} / \mathrm{m}^{3}$ deducted from soil phase relationships (Equations 10 and 11)."

3.11 Figure 6 , stage $C$ (density function): for the "porosity-lime index $\wedge 0.16$ " values lower than around 27.5 , there is no curve or relationship on the graph. Is this value the threshold and any lower value would result in dry unit weight of $19 \mathrm{kN} / \mathrm{m}^{3}$ as the optimum value? This needs more clarification.

Explanation of the model was now modified. Accounting for low binder content/high dry unit weight combinations (Lines $L_{3}$ and $\gamma_{19}$ ), the point where the porosity-lime index is around 27.5 (intersection of Lines $L_{3}$ and $\gamma_{19}$, named I) represents the maximum dry unit weight capable of being compacted $\left(19 \mathrm{kN} / \mathrm{m}^{3}\right.$ determined by modified proctor test) using the minimum lime content [3\% determined by lime fixation point Hilt and Davidson (1960)]. Therefore, porosity-lime index less than 27.5 are not possible to obtain by keeping $3 \%$ lime, the binder content has to be increased (Line $\gamma_{19}$ represents different lime contents at $19 \mathrm{kN} / \mathrm{m}^{3}$ ).

The new paragraphs are shown below:

"In this section, a graphical use of the decision-making model for optimal dosages is described. Figs. 4(a-g) show the decision-making model considering the economic and environmental pillars of sustainable development. In a first stage, the target value for the desired performance is determined, so the porosity-binder index $\left(\eta / L_{i v}{ }^{0.16}\right)$ required for such performance is obtained. Several mixtures design and protocols can be found in the literature and the strength requirements for using lime stabilized solutions as structural layers in pavement systems vary considerably from agency to agency (Little 1998). In this example, the mixture design is defined by Thompson (1970) criteria showed in Table 5 for bases in no freeze-thaw activity on structural layer. Thus, 28 days of curing minimum strength of $1,034 \mathrm{kPa}$ in unconfined compressive strength is selected for the design of base layers. The porosity-binder index $\left(\eta / L_{i v}{ }^{0.16}\right)$ required for such performance is then 32.44 according to point A in Fig. 4(a). Moreover, in cases where more than one design parameter is required, other performance requirements such as tensile strength [Figure 4(b)], and initial shear modulus [Figure 4(c)] can be assessed for the design porositybinder index.

The porosity-binder index 32.44 (required for the compressive strength for the example considered) can be attained by different combinations of dry unit weight and binder contents as long as the base layer construction and compaction are possible. These combinations are represented by the quadrilaterals illustrated in Figs. $4(\mathrm{~d}-\mathrm{g})$ for economic and environmental impact evaluated in Fig. 3. Lines $L$ represent the variation of dry unit weights at constant lime contents ( $3 \%$ for $L_{3}$ and $7 \%$ for $L_{7}$ ) for different porosity-binder indexes whereas Lines $\gamma$ show the variation of lime contents at constant dry unit weights $\left(16 \mathrm{kN} / \mathrm{m}^{3}\right.$ for $\gamma_{16}$ and $19 \mathrm{kN} / \mathrm{m}^{3}$ for $\left.\gamma_{19}\right)$. Achievable dry unit weights are conditioned by the equipment to be used in field (compactionrollers) whereas the minimum lime content ( $3 \%$ in this study) by methods such as the one described by Hilt and Davidson (1960). In this model, the maximum dry unit weight that can be achievable by typical compaction-rollers is limited by the value obtained in modified Proctor tests $\left(19 \mathrm{kN} / \mathrm{m}^{3}\right)$ and is represented by Lines $\gamma_{19}$ [Figs. $4(\mathrm{~d}-\mathrm{g})$ ]. The minimum lime content $(3 \%)$ is represented by Lines $\mathrm{L}_{3}$ [Figures $4(\mathrm{~d}-\mathrm{g})$ ]. Therefore, optimum dosages (low binder/high dry unit weight) are captured by solid lines Line $L_{3}$ and Line $\gamma_{19}$ in Figs. $4(d-g)$, and their intersections (points I) depict the minimum porosity-binder index $\left(\eta / L_{i v}{ }^{0.16}=26.94\right)$ available for optimum lowest binder $(L=3 \%) /$ highest dry unit weight $\left(\gamma_{d}=19 \mathrm{kN} / \mathrm{m}^{3}\right)$. For optimum porosity-binder index less than 26.94 an increment on lime content is inevitable (points will be on Lines $\gamma_{19}$ ). 
Finally, the minimal values of cost and environmental impacts (embodied energy, carbon dioxide emission, or photochemical oxidation) obtained from these lines for the design $\eta / L_{i v}{ }^{0.16}=32.44$ are evident by dashed arrows in Figures $4(\mathrm{~d}-\mathrm{g})$. Thus, the optimum low binder/high dry unit weight combination from $\eta / L_{i v}{ }^{0.16}=32.44$ (for the compressive strength for the example considered) is composed by a lime content of $3 \%$ and dry unit weight of $17.44 \mathrm{kN} / \mathrm{m}^{3}$ deducted from soil phase relationships (Equations 10 and 11)."

3.12 The English language (British or American) should be consistent. Example: the word "stabilization" in the Title, line 12, line 46 and line 62. Please check throughout.

The authors have now adopted the American English for the whole manuscript.

\subsection{Line 120: correct the grammatical error.}

Corrected as requested.

\subsection{Line: 289: replace "after" with "then".}

Replaced as requested. 
Click here to access/download Track Changes Version ACV costs (track changes version)v3.docx 